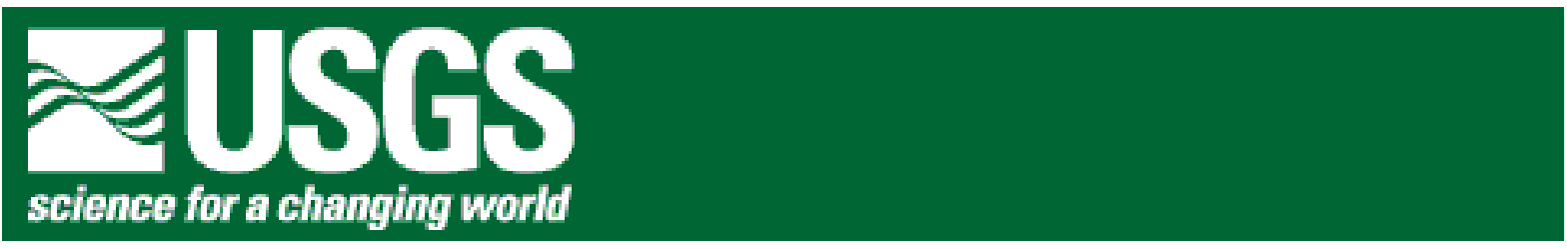

\title{
Inorganic Chemical Analysis of Environmental Materials-A Lecture Series
}

Open-File Report 2011-1193

U.S. Department of the Interior U.S. Geological Survey 


\section{U.S. Department of the Interior \\ KEN SALAZAR, Secretary}

\section{U.S. Geological Survey \\ Marcia K. McNutt, Director}

U.S. Geological Survey, Reston, Virginia 2011

For product and ordering information:

World Wide Web: http://www.usgs.gov/pubprod

Telephone: 1-888-ASK-USGS

For more information on the USGS-the Federal source for science about the Earth, its natural and living resources, natural hazards, and the environment:

World Wide Web: http://www.usgs.gov

Telephone: 1-888-ASK-USGS

Suggested citation:

Crock, J.G., and Lamothe, P.J., 2011, Inorganic chemical analysis of environmental materials-A lecture series: U.S. Geological Survey Open-File Report 2011-1193, 117 p.

Any use of trade, product, or firm names is for descriptive purposes only and does not imply endorsement by the U.S. Government.

Although this report is in the public domain, permission must be secured from the individual copyright owners to reproduce any copyrighted material contained within this report. 


\section{Contents}

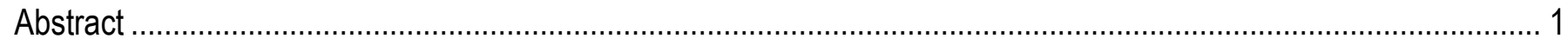

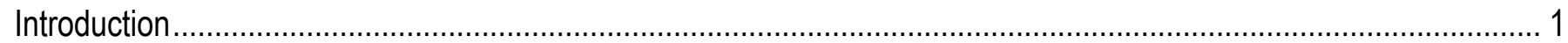

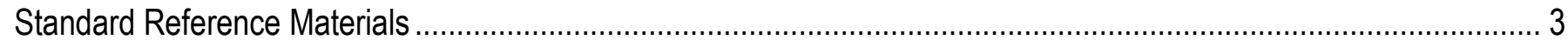

Development of QC materials matrix matched to a project study area - an example............................................ 4

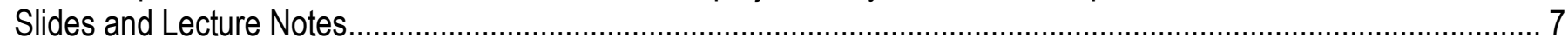

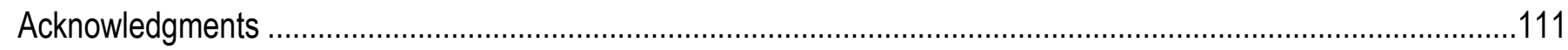

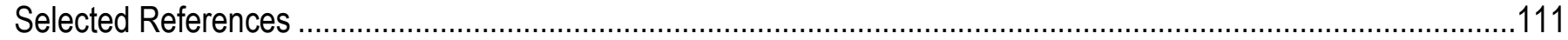

\section{Figures}

1. Major element comparisons in QC material versus median element concentrations in Pebble Deposit study........ 5

2. Minor and trace element comparison in QC material versus median element concentrations in Pebble Deposit study. 5

3. Minor and trace element comparison in QC material versus median element concentrations in Pebble Deposit study.

4. Minor and trace element comparison in QC material versus median element concentrations in Pebble Deposit study..... 6

Table

1. Atomic Spectroscopy detection limits (ppb or micrograms/liter). 108 


\title{
Inorganic Chemical Analysis of Environmental Materials-A Lecture Series
}

\author{
By J.G. Crock and P.J. Lamothe
}

\begin{abstract}
At the request of the faculty of the Colorado School of Mines, Golden, Colorado, the authors prepared and presented a lecture series to the students of a graduate level advanced instrumental analysis class. The slides and text presented in this report are a compilation and condensation of this series of lectures. The purpose of this report is to present the slides and notes and to emphasize the thought processes that should be used by a scientist submitting samples for analyses in order to procure analytical data to answer a research question. First and foremost, the analytical data generated can be no better than the samples submitted. The questions to be answered must first be well defined and the appropriate samples collected from the population that will answer the question. The proper methods of analysis, including proper sample preparation and digestion techniques, must then be applied. Care must be taken to achieve the required limits of detection of the critical analytes to yield detectable analyte concentration (above "action" levels) for the majority of the study's samples and to address what portion of those analytes answer the research question - total or partial concentrations. To guarantee a robust analytical result that answers the research question(s), a well-defined quality assurance and quality control (QA/QC) plan must be employed. This QA/QC plan must include the collection and analysis of field and laboratory blanks, sample duplicates, and matrix-matched standard reference materials (SRMs). The proper SRMs may include in-house materials and/or a selection of widely available commercial materials. A discussion of the preparation and applicability of in-house reference materials is also presented. Only when all these analytical issues are sufficiently addressed can the research questions be answered with known certainty.
\end{abstract}

\section{Introduction}

The precise and accurate analyses of environmental materials, including geological, biological, and man-made matrices, form the basis for most environmental studies. The analysis of environmental materials, including fresh and weathered metal-mining waste products, includes both laboratory-based determinations of the stable or stabilized analytes, as well as the in-field determination of the non-stable analytes. Difficulties in providing such analyses include the large range of analyte and matrix element concentrations, phase associations of the analyte elements, sample size (too small or too large), sample homogeneity, analyte volatility or stability, and contamination. Current trends in analytical chemistry focus on: lower detection limits (at least in the low $\mu \mathrm{g} / \mathrm{kg}$ range) and smaller sample sizes for simultaneous multi-element determinations; automation of the sample digestion/preparation methods; automation of data handling; and species characterization (phase association and/or valence) state. The growth in environmental analytical 
chemistry has also given rise to increased awareness of the need for a wide range of appropriate standard reference materials, both for total analyses and for operationally defined extraction procedures or speciated analyses.

There are many complete references for the analysis of environmental and geological materials available. Some of the more noteworthy are Carter (1993), Jeffery and Hutchison (1983), Ingamells and Pitard (1986), Keith (1992), Potts (1987), Smith (1994), Smoley (1992), Sparks (1996), Stoch (1986), and Westerman (1990).

One of the most important aspects to the analysis of environmental materials is the digestion/decomposition of the material prior to presenting the sample to the individual instrumental method. Excellent references for the total dissolution of environmental materials include Bock (1979) and Sulcek and Povondra (1989). Chao (1984) addresses in detail the application of partial and sequential dissolution schemes. Chao and Sanzolone (1992) discuss both total and partial dissolution techniques, as well as their application. Often, a method of determination is not sensitive enough, either because the original concentration of the analyte is too low or the required dilution of the resulting digestate is too high. Often, the separation and (or) preconcentration of the analyte from the matrix is required. Minczewski and others (1982) present a comprehensive overview of these useful techniques.

Sample dissolution is usually the most tedious, time-consuming, and limiting factor in chemical analyses. A multi-acid digestion, combining hydrofluoric, hydrochloric, nitric, and perchloric acids at low temperatures and pressures (Crock and others, 1983; Taggart, 2002), is a common dissolution method. Many of the common rock-forming alumino-silicate minerals can be dissolved by this method. The advantages of acid digestion are the ease of the method, use of large samples (as much as $2 \mathrm{~g}$, although $0.2 \mathrm{~g}$ is more common), low reagent blanks, and low total dissolved salts in the analytical solution. With an acid digestion, the final dilution factor commonly is less than 100, allowing many elements to be determined at or near their crustal abundance. One disadvantage of acid digestion using hydrofluoric acid is the volatilization of some elements, such as silicon and boron, as fluoride compounds. Commonly, a higher pressure, closed-vessel "bomb" digestion used in conjunction with a complexing agent (for the excess fluoride) is used to avoid volatilization of silicon and boron.

Some minerals are resistant to routine acid digestions and require a more rigorous digestion. These minerals include spinels, beryl, tourmalines, chromite, zircon, monazite, niobates, tungstates, topaz, and cassiterite. These minerals can be completely dissolved by the proper choice of a sinter or fusion digestion procedure. A sodium peroxide sinter will dissolve most resistant minerals (for example, Sulcek and Povondra, 1989). For example, boron and silicon are routinely determined in tourmaline by inductively coupled plasma-atomic emission spectroscopy (ICP-AES) following a sodium peroxide sinter in a zirconium crucible at $445^{\circ} \mathrm{C}$. Lithium metaborate, sodium and (or) potassium hydroxide, sodium carbonate, and the alkali persulfates are commonly used as fusion reagents. However, there are drawbacks to the use of fusions or sinters. They introduce a much higher total salt content into the analytical solution, which can clog the nebulizer and torch assembly in ICP-AES and the interface cones in inductively coupled plasma-mass spectrometry (ICP-MS), leading to significant signal drift. These fusions and sinters also tend to have long-term memory effects and higher reagent blanks. A larger dilution factor is used because of the smaller sample size (10 to $100 \mathrm{mg}$ is common) in a larger final solution volume. The final dilution factor is commonly 200 to 400, making the determination of some trace elements impossible by ICP-AES direct aspiration without prior separation and preconcentration. Also, at least one element common to the reagent is not determinable, such as lithium and boron from a lithium metaborate fusion. 
With advancements in analytical instrumentation over the past three decades, the analyst has a choice of several precise and accurate methods with sufficient sensitivity for most environmental study requirements. Some of the more popular methods of spectrographic instrumental analysis are: flame atomic absorption spectroscopy (F-AAS), graphite furnace-atomic absorption spectroscopy (GF-AAS), inductively coupled plasma-atomic emission spectroscopy (ICP-AES), and inductively coupled plasma-mass spectrometry (ICP-MS). Table 1 presents a comparison of the detection limits for these spectrographic techniques. Few laboratories rely on only one of these analytical methods, but often use complimentary combinations of these techniques. Other methods of analysis commonly used in the laboratory for environmentally important analytes include X-ray fluorescence, instrumental neutron activation analysis, electrochemical methods (especially specific ion electrode methods), infrared detection of combustion products, ion chromatography, and colorimetry. Sandell (1959) offers a classic overview of many of the colorimetric methods and many applications. Skoog and others (2006) present a discussion of the other techniques.

\section{Standard Reference Materials}

The use of well-characterized, matrix-matched standard reference materials (SRMs) in any geological, geochemical, or environmental study involving any analytical data is critical for the study to withstand scientific scrutiny. The appropriate use of SRMs cannot be over emphasized. Issues of precision, the reproducibility and stability (both short-term and long-term), and accuracy (how close to the "true, absolute value" your measurement approximates) must be addressed and assessed. Issues of quality assurance and quality control (QA/QC) must be quantified. The prudent use of SRMs, laboratory and field duplicates, and laboratory and field blanks addresses these critical issues for the scientist. The use of SRMs is discussed at length by Taylor (1993). An excellent compilation of geochemical SRMs and their compositions is presented by Potts and others (2000).

The issue of how well analytical laboratories perform on long-term or regional studies is a concern to many people. Incorporating QC materials into the sample submittal process is one way to address this issue but there are certain limitations that should be recognized. One of the main issues is the importance of matrix matching samples and QC materials. The effect of mineralogy and matrix can be significant in terms of chemical analysis, and if the QC material and samples differ significantly, a false sense of laboratory performance can be realized, particularly for the efficacy of sample preparation methods. This problem is further complicated by analysts not having an extensive supply of QC materials that cover a wide range of sample types from which they can draw. This means that often a reduced number of QC samples are submitted and something off the shelf is selected which has the same general description (rock, soil, sediment, and so forth).

The USGS is actively involved in the world community of producing and certifying geological SRMs. Consult http://minerals.cr.usgs.gov/geo_chem_stand/for details of the USGS SRM project. The USGS Geochemical Reference Materials project provides geochemical reference materials for use by scientists in all areas of earth science throughout the world. The majority of USGS reference materials are based on silicate rocks that were collected from the continental United States and Hawaii and range in composition from basalt to shale. The composition of these reference materials has been determined through rigorous testing procedures by multiple laboratories using a wide variety of analytical techniques. The reference materials are suitable for use in calibration of analytical instrumentation, testing analytical methodologies, and 
for use as quality control samples. For more information on this program please see Wolf and Wilson (2007).

\section{Development of matrix-matched QC materials to project study area-an example}

Recently, a different approach was taken in the development of QC material for the Pebble copper deposit study in Alaska (Anderson and others, 2011). Rather than rely on stock QC material, one was developed for the project using the splits of samples collected. We believe that this approach offers several scientific advantages, as well as a cost effective way to produce QC material that provides the best possible test of laboratory performance.

One of the challenges associated with developing a QC program for long term or large scale geochemical studies is to find high quality reference materials in sufficient quantities that match the lithology of the area under investigation that will be available for the duration of a multi-year study. Issues pertaining to sample decomposition and inter-element interferences often have a profound impact on the quality of analytical results. This is why matrix-matched QC materials are highly desirable in order to monitor laboratory performance. Traditionally, established reference materials are selected as QC materials that have the same general identifier (for example, soil or sediment) with little regard to their mineralogical composition, especially as it compares to the study area under investigation. This can lead to an erroneous evaluation of laboratory performance, especially if the QC materials are more or less easily digested/analyzed as compared to the typical study area sample.

For this Pebble copper mine study, after discussion with project staff, a plan was developed that utilized the samples already collected as the feedstock for the desired QC material. The collected samples were split and a portion set aside for QC preparation. Approximately $45 \mathrm{~kg}$ were obtained in this manner for an in-house QA/QC material. The material was then ground, blended, and split into containers using the procedures developed for normal USGS geochemical reference materials preparation. Consult http://minerals.cr.usgs.gov/geo_chem_stand/ for details of the sample preparation methods. Aliquots were submitted to the USGS contract laboratory as part of the normal sample stream and analytical results compiled. A series of total element and partial extraction analyses were performed using techniques from a variety of laboratories. Target element concentrations were determined from these tabulated values and used to evaluate laboratory performance.

Using information provided by study geologists, a comparison was made of average QC element concentrations values with median values from the study. Only the USGS contract laboratory's 55 element analytical package was used in this comparison (details of this method given at: http://minerals.cr.usgs.gov/intranet/chem/labmethods.html\#m22). If the prepared QC material was representative of the "average" study area soil, then for any/all element(s) the ratio of QC concentration versus median study value should yield a value of one. A graphical presentation of major and minor elements quantified is presented below in Figures 1-4. 


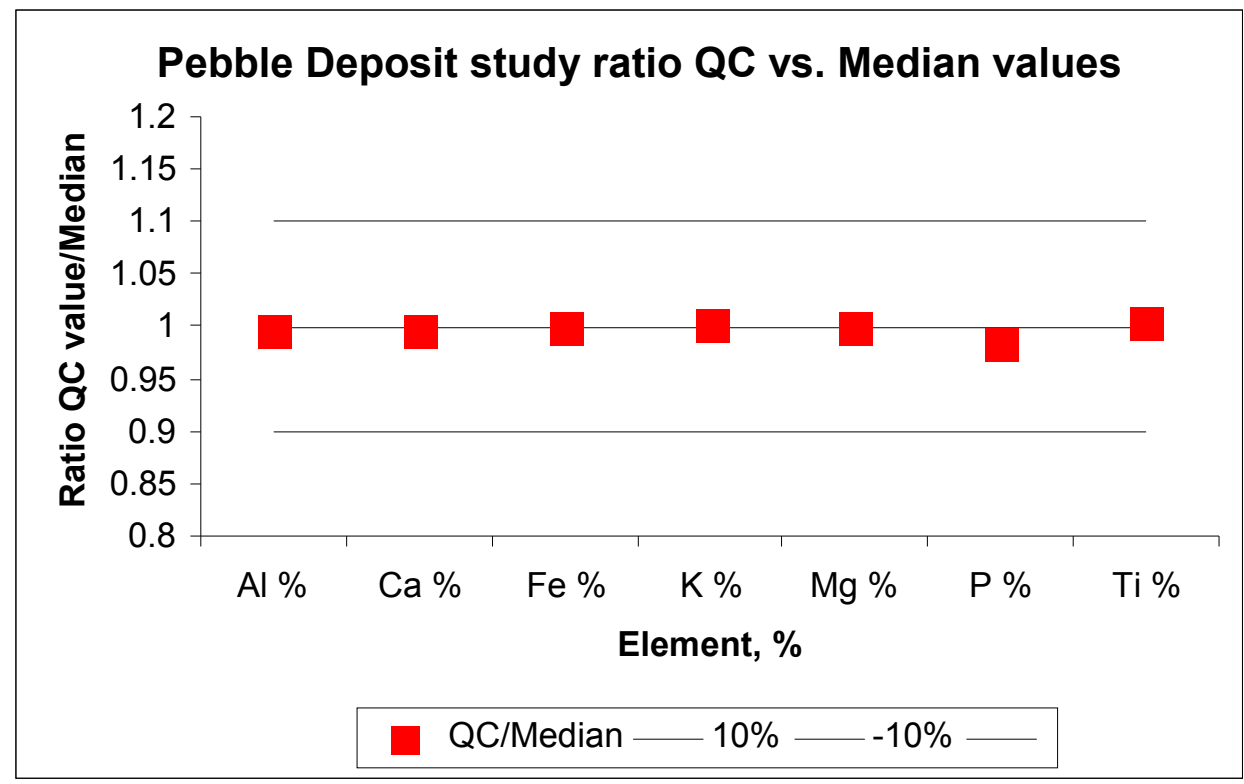

Figure 1. Major element comparisons in QC material versus median element concentrations in Pebble Deposit study.

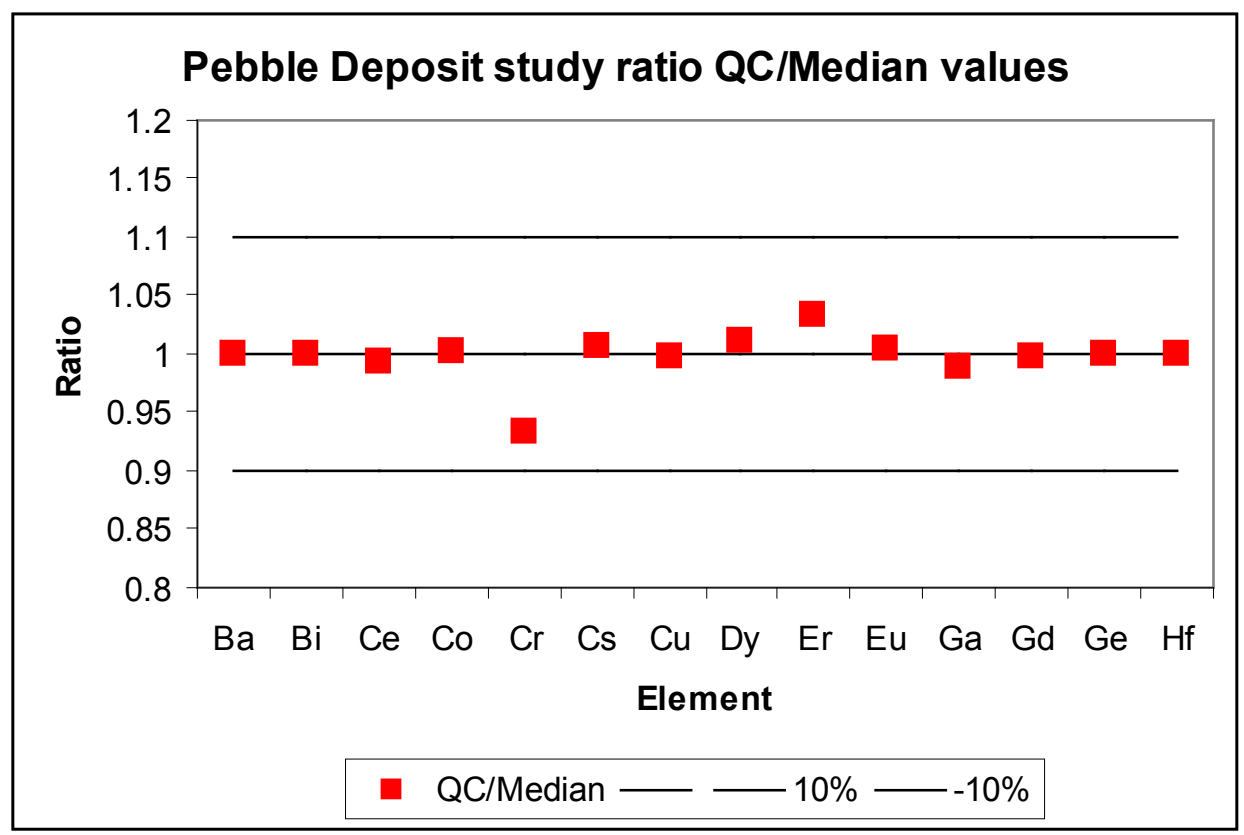

Figure 2. Minor and trace element comparison in QC material versus median element concentrations in Pebble Deposit study. 


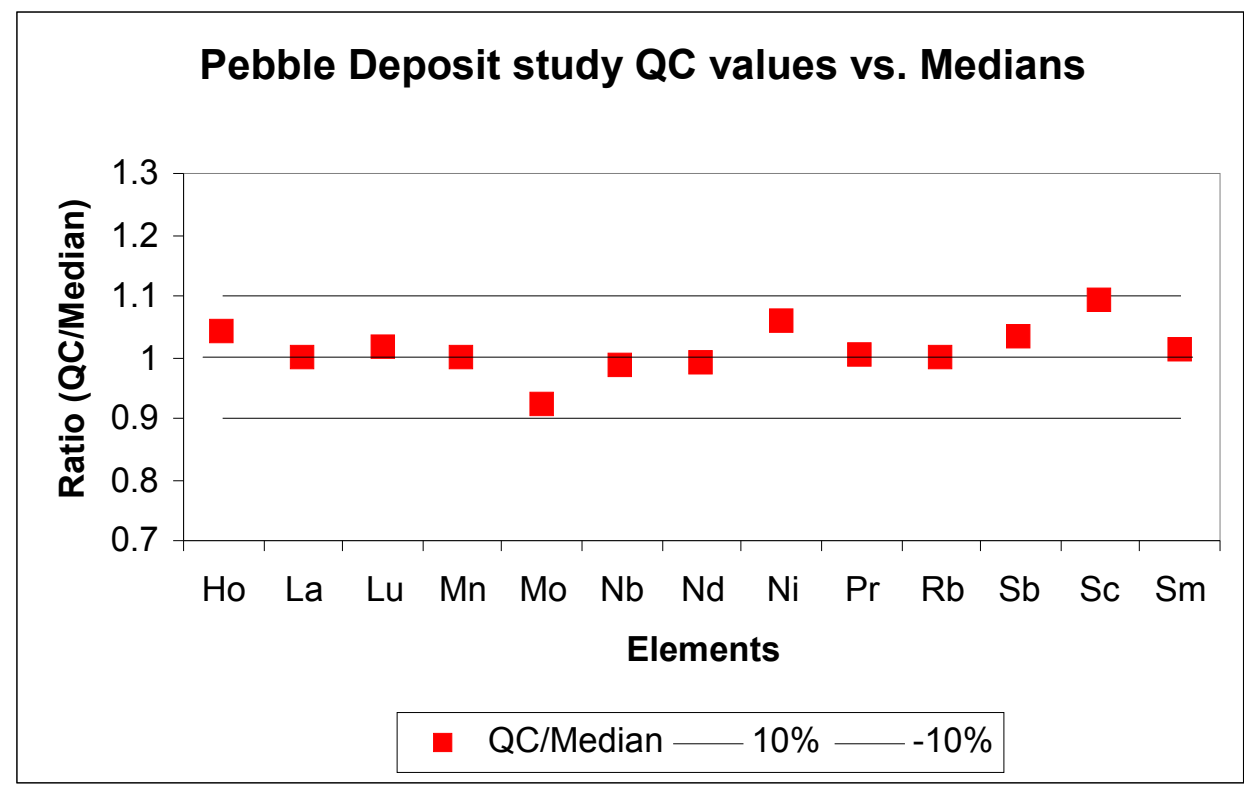

Figure 3. Minor and trace element comparison in QC material versus median element concentrations in Pebble Deposit study.

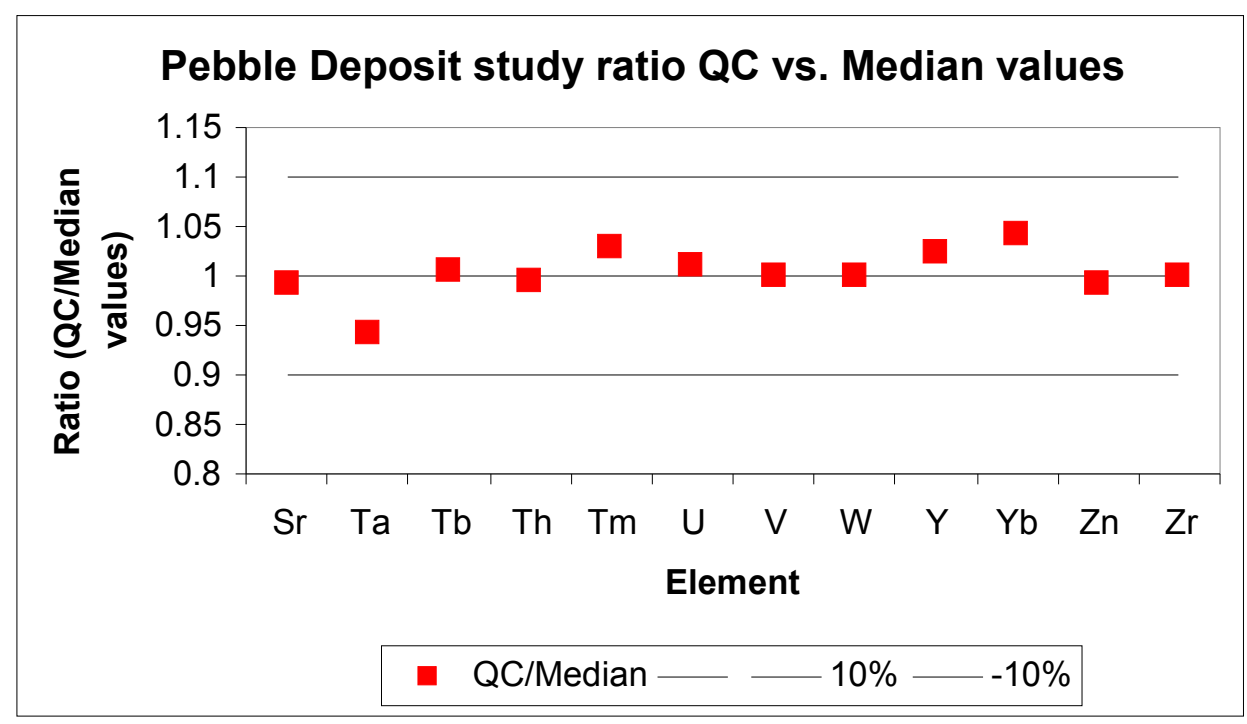

Figure 4. Minor and trace element comparison in QC material versus median element concentrations in Pebble Deposit study. 
Based on historical results from USGS contract laboratories, it is anticipated that a \pm 10 percent level of uncertainty is the upper limit expected for this type of comparison. Element ratios outside this value suggest that either a bias exists between the two sample types or that there are analytical issues associated with the analyses. An examination of Figures 1 through 4 suggests that the QC material aligns itself well with the median concentrations observed in the study.

It is apparent that, for the majority of elements studied, the composite QC approach provides a suitable mechanism for the development of a study QC material. In addition to providing a material with a reasonable matrix composition, the cost associated with this approach can be reasonable if the optimal amount of material is prepared and the container costs are minimized. Improvements to this approach can be expected if the following improvements are considered: (1) Better initial planning in terms of sample collection so that QC material(s) is/are prepared before the major sample load arrives at the laboratory. This may require an initial sample reconnaissance effort to collect typical sample types. (2) Collection of sample amounts are in excess of anticipated laboratory needs. (3) Analysis of composite QC material is made alongside certified reference materials so that traceability is established to primary reference materials. Doing so improves the reliability factor for QC data. (4) Earlier coordination with research chemistry group for preparation of QC material.

\section{Slides and Lecture Notes}

The following series of slides and associated lecture notes is a condensation of several lectures presented by the authors at the Colorado School of Mines (CSM), Golden, Colorado. Additional material was also presented by the authors at various lectures in the past; it is included here to supplement the original CSM lecture material. 
Slide 1

\title{
Inorganic Chemical Analysis of Environmental Materials
}

\author{
J. G. Crock and P.J. Lamothe \\ Crustal Geophysics and Geochemistry Science Center \\ Denver, Colorado \\ U. S. Geological Survey
}

\section{₹USGS \\ science for a changing world}

The accurate analysis of environmental materials - including biological, geological, and man-made matrices - form the basis for most environmental studies. Although the title says this report and presentation are on the chemical analysis of environmental materials, we will include information on sampling, quality assurance, and control. Soil will be our primary example of an environmental material. This discussion can be extended to include many man-made materials, especially those that are silicate based, ceramics, concrete, or other road building materials.

Difficulties in providing unbiased determinations include the large range of analyte and matrix element concentrations, phase associations of the analyte element, sample size (too small or too large), sample homogeneity, analyte volatility, and sample contamination. Current trends in analytical chemistry relate to lower detection limits (at least in the low $\mu \mathrm{g} / \mathrm{Kg}$ range) simultaneous multi-element determinations, automation of the sample digestion/preparation, automation of data handling and storage, and species characterization (phase association and/or valence). The growth in environmental analytical chemistry has also given rise to increased awareness of the need for a wide range of appropriate standard reference materials, for both total and partial analyses. 
Slide 2

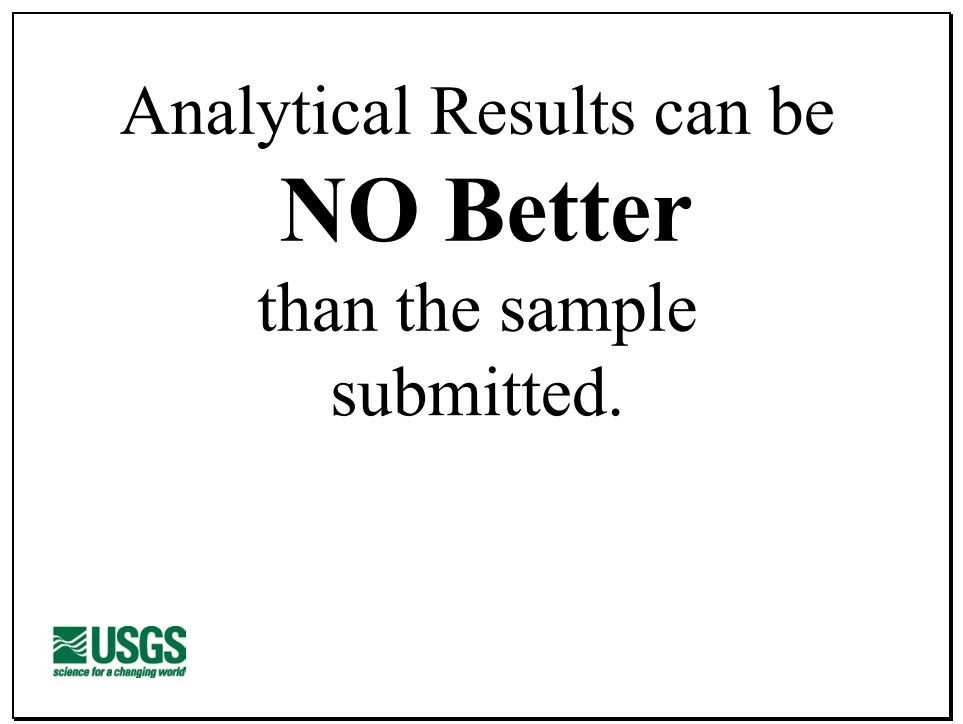

First and foremost, analytical results can be NO BETTER than the sample submitted to the laboratory. Also remember that you will never determine the absolute true answer, but you can attempt to make a reasonable estimate of it. Another way to look at this statement is "Garbage in is garbage out!" The final scientific interpretation is only as good as the analytical data and the analytical data can only be as good as the sample taken and analyzed. Sample size can range from an entire outcrop of rock down to microscopic inclusions in a solid, and everything in between. The sample taken must be representative of the population that answers the question being asked. Samples can range from that single inclusion to a large composited sample made from tens of subsamples. Sample mass required for a representative sample increases as the particle size of the material increases, as the sample exhibits increasing heterogeneity as the concentration of the desired analyte decreases, and as the desired degree of confidence increases. 
Slide 3

\section{What Really Is An Environmental Material?}

- Naturally occurring materials including flora, fauna, aqueous materials, soils, rocks, weathering products, ores, coal, peat, ashes, and sediments

- Man-made materials including slags, manufactured products and by-products, effluents, and waste stream

\section{USGS}

Environmental sciences incorporate most of the physical world around us. If it can be collected, preserved, and stored, chances are it will eventually be analyzed for an environmental study. The accurate analysis of environmental materials for their total or partial elemental content is anything but a simple or routine task. There are numerous problems that must be addressed to ensure a high quality analysis. The first and foremost problem to address is what question does the environmental scientist need answered. Does the scientist need an average concentration of an analyte for a volume or area, or is a distribution map required? Is the scientist asking for elemental speciation, phase association, or would a total analysis answer the correct question? The scope of the phrase "Environmental Materials" is where the semantic problems continue. Most naturally occurring materials and some man-made materials will fall into this classification. The concentration of an element of interest commonly ranges from less than one part per billion (microgram per kilogram or $\mu \mathrm{g} / \mathrm{Kg}$ ) to the tens of weight percent. Furthermore, there are several potential sampling problems in the analysis of environmental samples. 
Slide 4

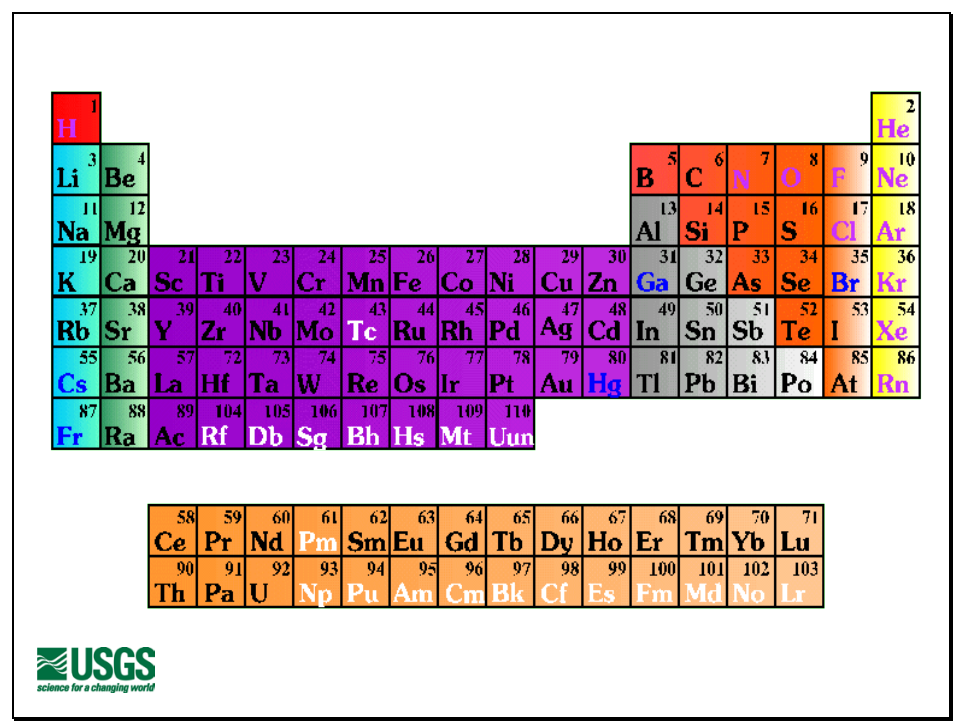

What element or group of elements will answer the study's question or questions?

Environmental studies usually require data about a large portion of the elements in the periodic table to understand and answer the posed questions. Also, many environmental studies require the analyses of many samples, often in multiple matrices or on different fractions of a given matrix. This would include the analyses of water, stream bed sediments, rocks, soil, different soil horizons, and various parts of plants. 
Slide 5

\section{What Really is the Question?}

- Average concentration of a given layer or volume or is a distribution map required?

- Elemental speciation or phase association?

- Total analysis?

- Required regulations to meet?

- What is the population to be described?

- What question does the customer or end users of the data need to have answered?

\section{USGS}

The very first hurdle to clear for meaningful analytical data to be obtained is, "What is the question to be answered with the analytical data?" The question to be answered by the study and the sampling must be clearly defined first. Only after the question is defined can a sampling and analytical protocol be defined and implemented. 
Slide 6

What? Why? When? How?
•What medium to sample - must define the
target population and how sampled
•Reasons for sampling
•Question(s) to be answered
•Desired degree of statistical confidence in
the answer(s)
•When to sample - temporal issues
You'll never know the "true" answer, but you
can make a reasonable estimate of the truth!!
₹USGS

These questions are critical to be answered prior to the beginning of any sampling campaign. Only when these are addressed sufficiently prior to sampling will the samples presented to the analytical chemist be of use to answer the appropriate questions with any degree of confidence. 
Slide 7

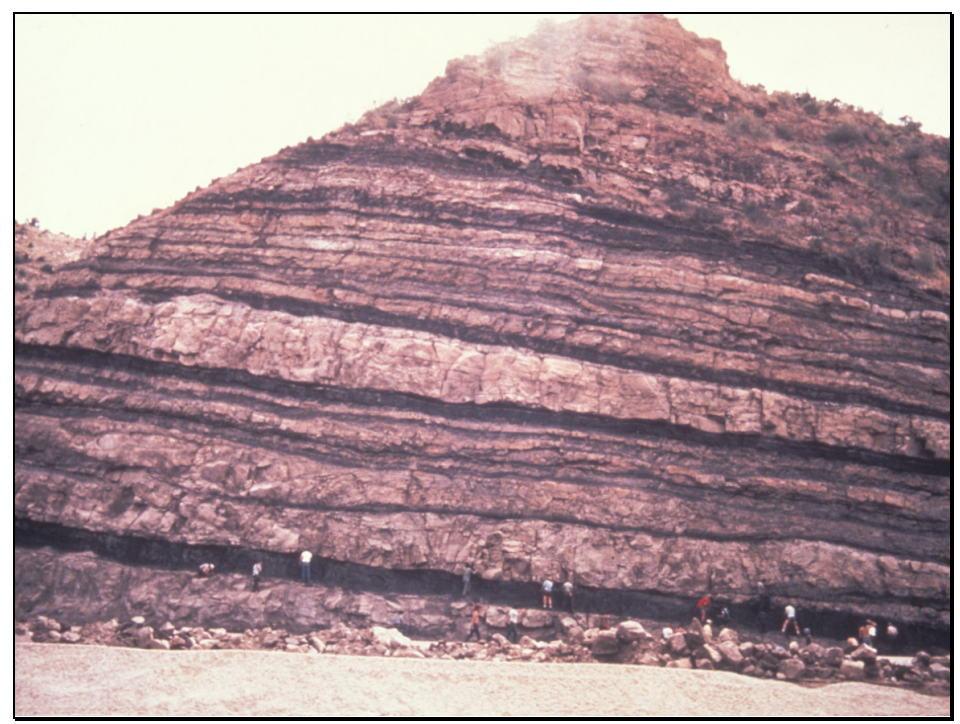

This is an example of a stratified outcrop in Utah of mixed lithologies. Does the question ask the composition of the entire outcrop, a given layer, or a group of layers? Although this is an extreme visual example of outcrop variability and heterogeneity, similar features can occur at all scales of an outcrop to the thin section and must be addressed. This stratification also applies to soils - what horizon or composited depth sample will answer the defined question? 
Slide 8

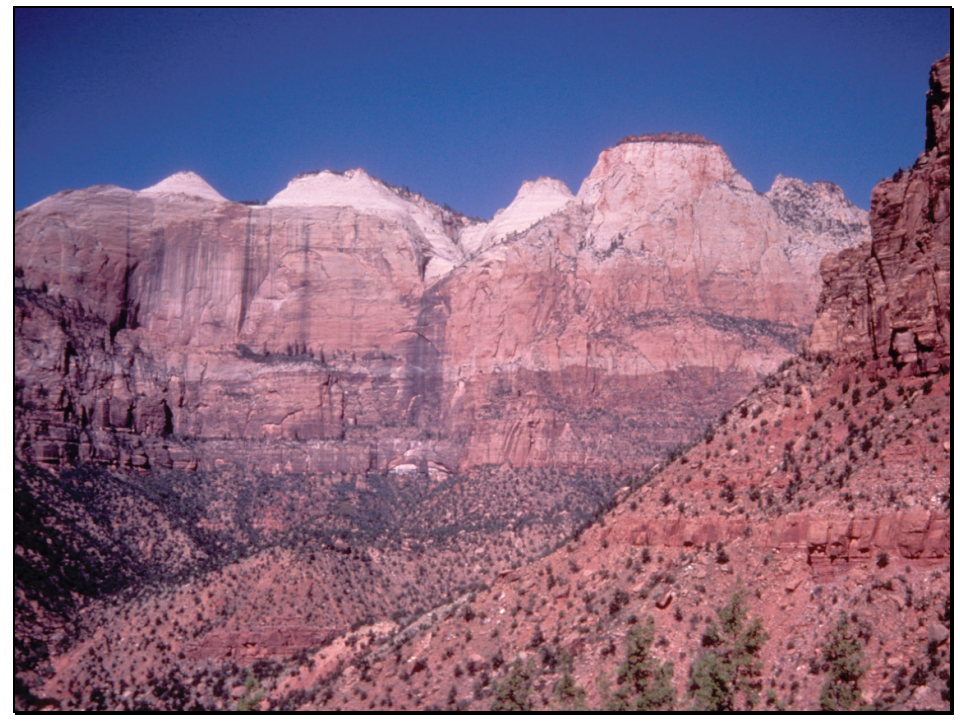

Although this massive sandstone outcrop from Utah could appear to be homogeneous from a distance, scale and sampling issues must be addressed prior to the collection of samples. 
Slide 9

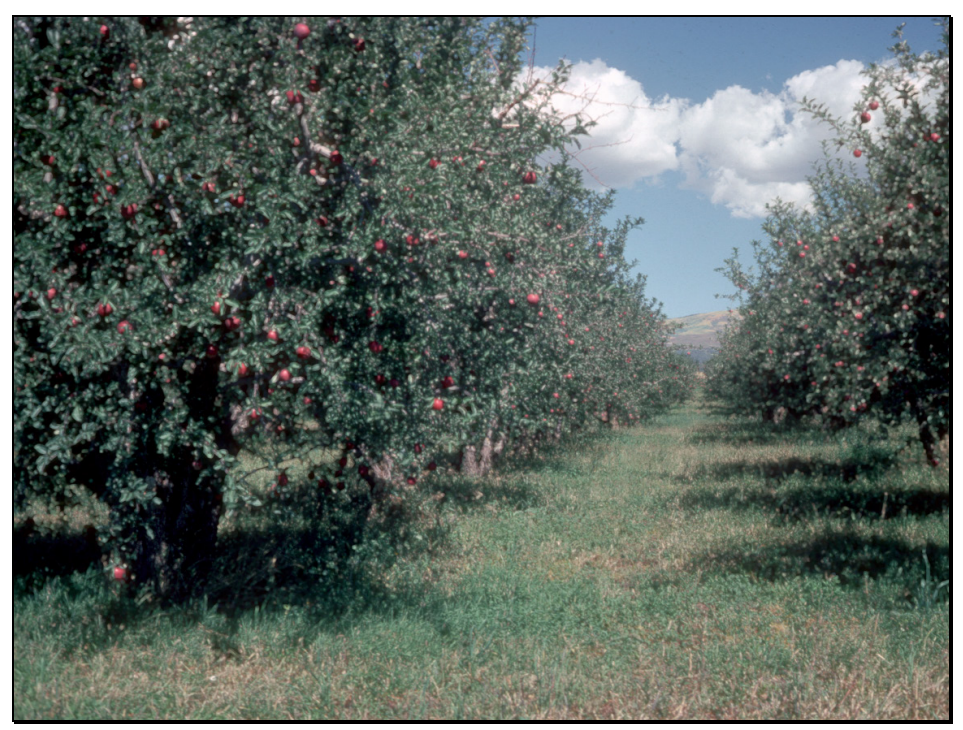

For vegetation, one must define which part of the plant is to be sampled-leaves, twigs, bark, woody parts, fruit, roots, or a combination? All parts react differently when exposed to given elements and will tell a different story. Essential versus non-essential elements of plants respond differently in the part samples. Non-essential elements tend to concentrate in the leaves, fruit, and seeds since they are usually shed annually. Also, one must: (1) address whether or not to composite multiple plants in a given area or multiple plants from multiple areas; (2) consider the prevalence of a given species across the study area - the plant (same species, genus) must be present throughout the study area for usage; (3) determine whether to sample a native or invasive species or an agricultural/domestic species; and (4) be aware of the historical usage of land. In this orchard, for example, what type of herbicides and pesticides historically used will affect the soil's elemental composition; for example, $\mathrm{As}, \mathrm{Hg}$, or $\mathrm{Pb}$ ? 
Slide 10

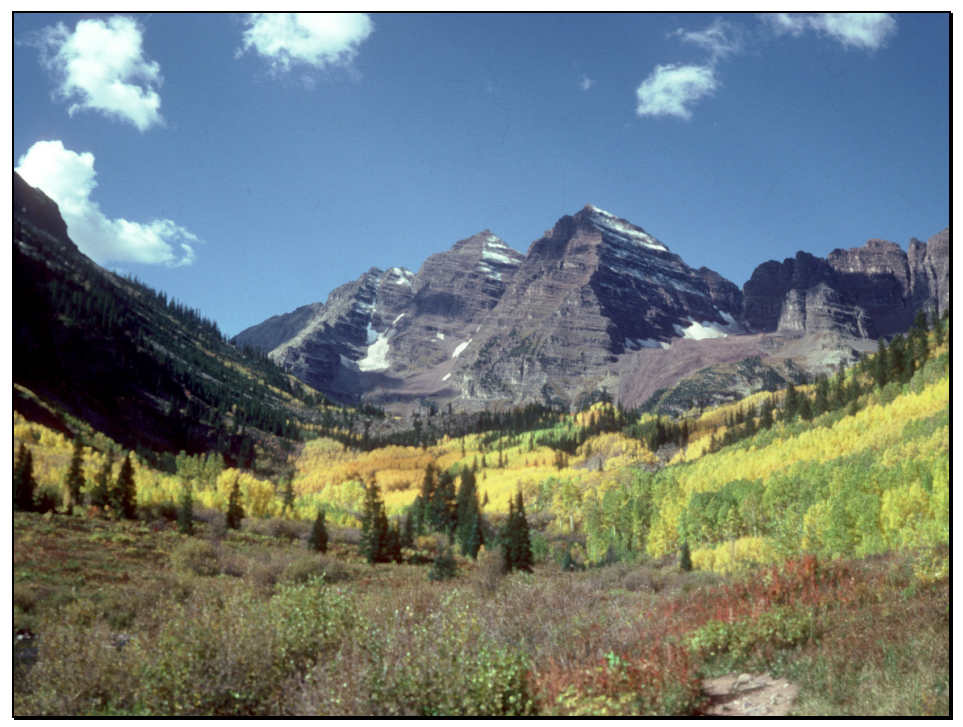

Temporal issues must also be addressed. This is especially true with water, soil, and vegetation samples. Not only does one need to be aware and consistent of the season the sample was collected, but even the time of day will affect the concentration of some analytes in water, as is shown in the next slide. 
Slide 11

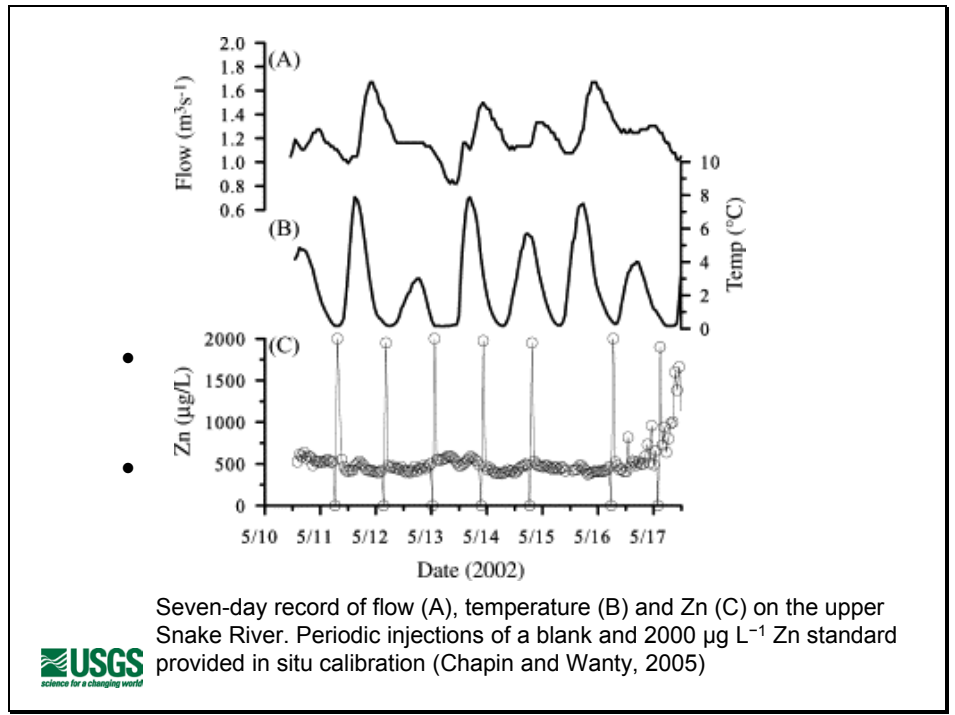


Slide 12

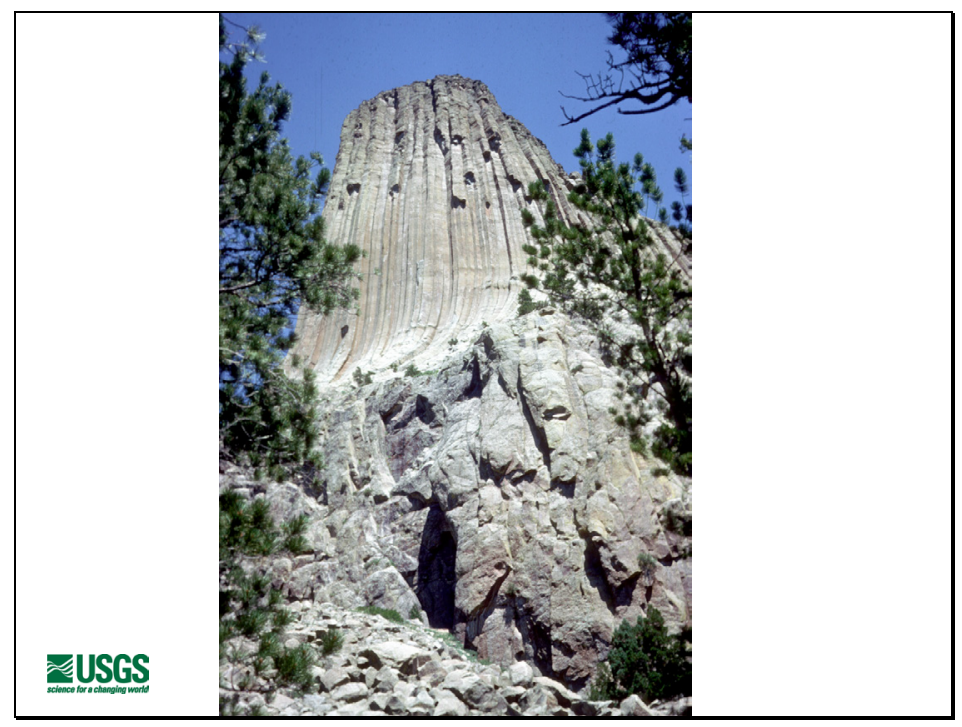

Is the sample collected at the base of Devil's Tower (Wyoming) the same material further up the tower? One must be very cautious of collecting float (material not attached to the original outcrop) and using that to infer the chemistry of the entire formation. The scientist must consider the amount of weathering present in a rock sample. Certain elements and mineral phases will differentially leach from the original material, causing either concentration or depletion of certain elements as weathering occurs. 


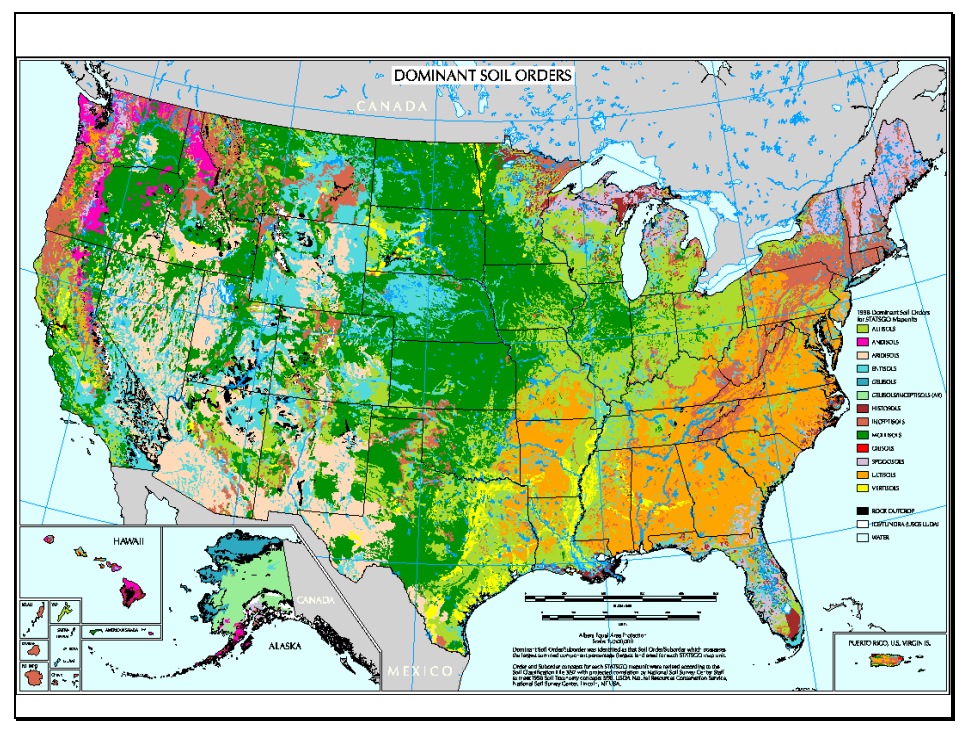

There are many different soils across the USA, as shown in this generic, low resolution soils map of the USA from the Natural Resources Conservation Service's (NRCS) STATSGO2 Database (http://soils.usda.gov/survey/geography/statsgo/description.html—Soil Survey Staff, 1999, Soil Taxonomy, A basic system of soil classification for making and interpreting soil surveys: United States Department of Agriculture, Natural Resources Conservation Service, Agriculture Handbook Number 436).

For any soil sampling scheme, an investigator is advised to consult with local soil maps and local agricultural experts. The type of soil that is predominant in an area will help determine the sampling scheme. The type of soil is a direct reflection of the combined effects of local climate and soil parent material.

There are many questions that must be addressed prior to sampling. These questions include the following:

- Is there an average concentration of a given layer, horizon, or volume? Or is a distribution map required?

- Elemental speciation or phase association?

- Total analysis?

- Required regulations to meet?

- Reasons for sampling?

- Desired degree of confidence in the answer(s)? 
Slide 14

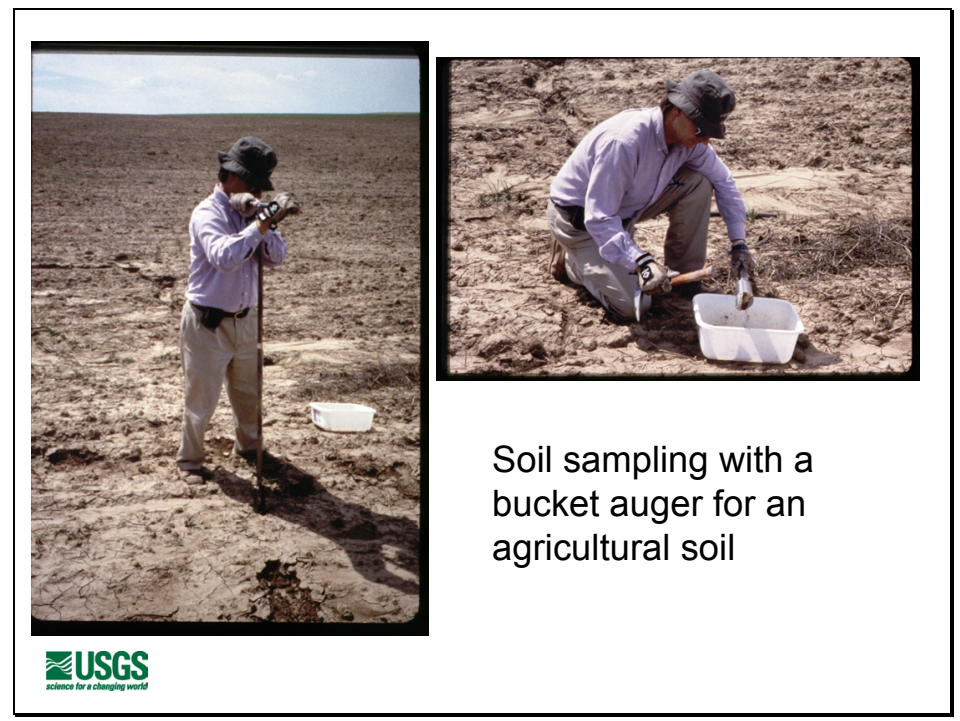

What is the type of soil to be analyzed? This is an agricultural soil in eastern Colorado being sampled to determine an average elemental content of the field's plow zone. For this study, the question required only one sample for analyses, but this one sample needed to be a composite of at least 30 subsamples through the plow zone (top 12 inches) taken from an evenly spaced grid placed over the field's planar dimensions. 
Slide 15

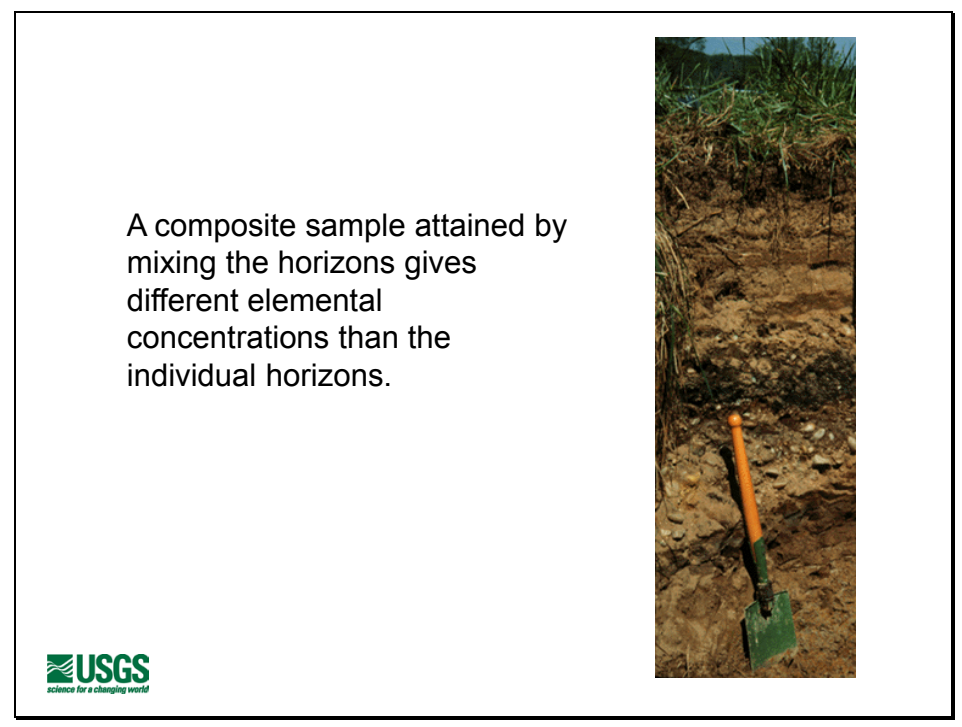

When compositing through a soil profile, take care to equally represent the entire profile and collect an appropriate amount from each profile. For example, if the B horizon is half of the exposed profile, the final composite sample must contain half the B horizon. Sample bias would occur if the texture or composition of a given layer would lead to over or under representation in the final composited material. 
Slide 16

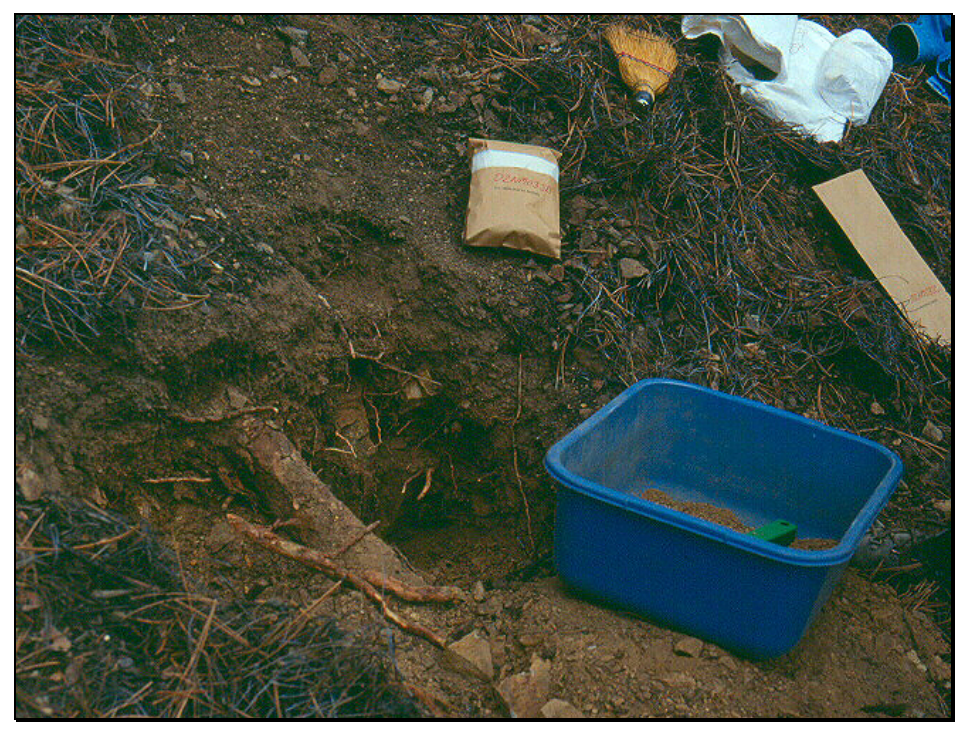

Are the soils alpine or forest sites? Here is a boreal soil from the Fortymile Mining District in east-central Alaska. Questions of what to include in the sample must be addressed. For example, defining horizons in these types of soils is often very challenging. Also, how much of the organic material should be incorporated into the final sample must be addressed. Commonly, loose roots, leaves, twigs, and other surface material are removed prior to compositing for the final field sample. Other material may be removed in the laboratory preparation, including rocks and more organic material, usually by sieving to a given mesh size (commonly -10 mesh or $2 \mathrm{~mm})$. 


\section{Inorganic Trace, Minor, and Major Element Composition}

- Total

- Extractable (operationally defined)

- Bioavailable/Accessibility

\section{:USGS}

The question of what is to be determined must be addressed prior to any analytical effort. Any partial digestion procedure will give different results when compared to a true total digestion. A true total digestion implies that the entire sample is dissolved with no material either precipitated, suspended, or undigested in the analytical solution. 


\section{Variables to Consider When Choosing a Method of Analysis}

- Qualitative or quantitative information - Must be robust!

- Detection limit and precision required?

- Multi-element or single-element determinations?

- What methodology and facilities are available?

- Budget and resources - number of samples in what time frame?

- What is the operators' required skill level for operating instrumentation and performing the digestions?

\section{₹USGS}

There are many variables to consider when choosing an analytical scheme to answer the prenominate questions. Again, these questions must be addressed prior to any analytical work. Careful forethought prevents unnecessary confusion and work for both the analytical chemist and the scientist using the analytical data. A chosen method of analysis should provide data for a set of samples above that method's detection or reporting limit. It usually does no good if the data set has a majority of its values for a given analyte as "ND - not detected" or " $<\mathrm{X}-$ less than the detection limit." 
Slide 19

\section{Hurdles to Consider for Quality Analytical Results}

- There may be a large and varied concentration range of the analytes and concomitant elements of concern.

- Is the analyte a major component of a trace phase (arsenic in arsenopyrite) or a trace component in a major phase (arsenic absorbed onto clays, oxy-hydroxides, or organic material)?

- Digestion method required - partial extraction or total.

- Precision and accuracy required (confidence level).

- Homogeneity of the sample - What sample size is required to give the required confidence in the data?

- Pretreatment required - in the field or laboratory.

\section{₹USGS}

There are many questions that must be addressed prior to sample collection and analysis. It is strongly advised that the scientist consult with the analytical staff prior to sampling and submission of samples for analytical work. 
Slide 20

\section{More Hurdles}

- Contamination is always a possibility, especially for trace analytes

- Interferences for the chosen method - both chemical and spectral

- Analyte speciation concerns

- Preservation of the sample; that is, freezing, type of sampling container (paper, cloth, or plastic bag, amber glass?, Teflon( $)$, acidification with which acid, drying in the field

- Transportation of the sample to the laboratory and the associated shipping regulations

- Representative sample of the population to be studied

\section{₹USGS}


Slide 21

\section{Yet Even More Hurdles to Consider}

- Volatilization of the analyte, such as $\mathrm{Hg}$, As, or Se

- Loss of analyte to the container walls

- Stability of the sample once collected - required (legal) holding times

- Collection of more than one sample split in different containers for different preservation method at the site for different analytical procedures

- Precipitation of the analyte during the digestion of the sample 
Slide 22

\begin{tabular}{|c|c|c|}
\hline \multicolumn{3}{|c|}{$\begin{array}{c}\text { Soil Parameter Measurements - Not } \\
\text { Discussed, but Important for Some Studies }\end{array}$} \\
\hline Salinity & Organic Matter & $\begin{array}{l}\text { Physical } \\
\text { Properties }\end{array}$ \\
\hline Soil gases & Organic Species & Mineralogy \\
\hline Soil pH & Nitrogen Forms & Gypsum \\
\hline Halogens & $\begin{array}{l}\text { Cation Exchange } \\
\text { Capacity }\end{array}$ & Soil Acidity \\
\hline Sulfur Forms & Redox Potential & Isotopes \\
\hline Carbon Forms & Nutrients & Saturation Index \\
\hline Life Forms & Radionuclides & Alkalinity $\approx$ USGS \\
\hline
\end{tabular}

There are many analytical measurements pertinent to soil studies that are beyond the scope of this report. Many of these measurements are unique to soils for agricultural studies indicating soil fertility and viability. Many of these measurements are also used in various environmental studies, especially soil $\mathrm{pH}$, isotopic composition (both stable and radioactive), and organic constituents. 
Slide 23

\section{Sample Collection Questions}

- Representative sample - ANOVA design

- Sample size collected - Containers-Paper,

- Homogeneity

- Drying, sieving

- Regolith - Composite or individual horizon

- Contamination (equipment and glass, plastic?

- Sample splits Bulk, Archive, Active

- Preservation

- Transportation/ - Regulations for DOT?

- Dept. of Agriculture?

- Customs

\section{₹USGS}

Ideally, these issues are addressed before the sampling begins in a collaborative arena between the analytical staff and the scientists performing the study. 


\section{Sampling Concerns (continued)}

- Sampling and analytical error

- Precision requirements (field and laboratory)

- Improper collection, including defining the target population, sampling location, spatial or temporal variation, sampling media, sampling tools and equipment, and calibration of instruments 
Slide 25

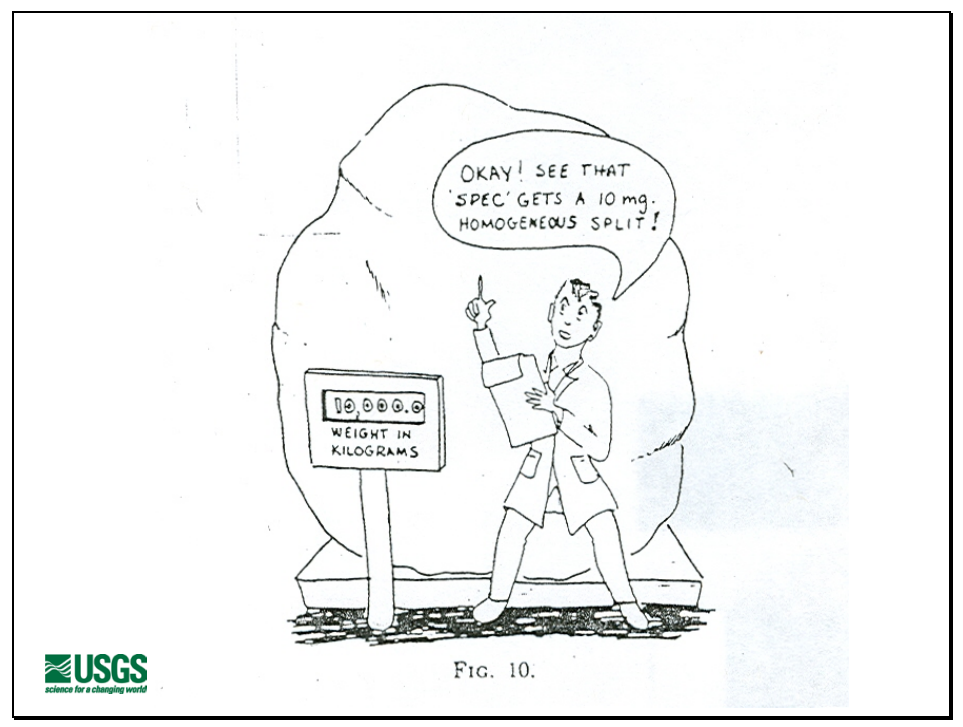

This tongue-in-cheek cartoon is from Rose (1979) and depicts the need for an appropriate sample size submitted to the laboratory for analyses. The analyst will always want sufficient material to run laboratory duplicates and, at times, spiked samples to test difficult or novel matrices. Too large (within reason) is always far better than too small. 
Slide 26

\section{Sample Preparation Questions}

- Are all procedures standardized to allow comparison of data between studies of the past, present, and future?

- Drying temperature - heated or ambient?

- Forced air or static conditions?

- Grind, disaggregate, or both?

- Sieving to what size fraction for total analyses and partial determinations - same or different?

- Grinding surface of the equipment used -steel, agate, tungsten carbide, or ceramic?

\section{₹USGS}

The final analytical results can never be better than the preparation of the samples. This part of any analytical procedure is critical for the successful analysis and final interpretation of the data. A study is quickly devastated by sample contamination, mislabeling, sample mix up, or mistreatment, especially by an incorrect choice of grinding media. Agate or ceramic grinding surfaces will contaminate with $\mathrm{Si}, \mathrm{Al}, \mathrm{Ca}, \mathrm{Mg}$, and other major elements, but are the preferred grinding surfaces when transition and trace metals are the major focus of the study. Many agricultural studies will use tungsten carbide or hardened steel when metals are not important to the study. 


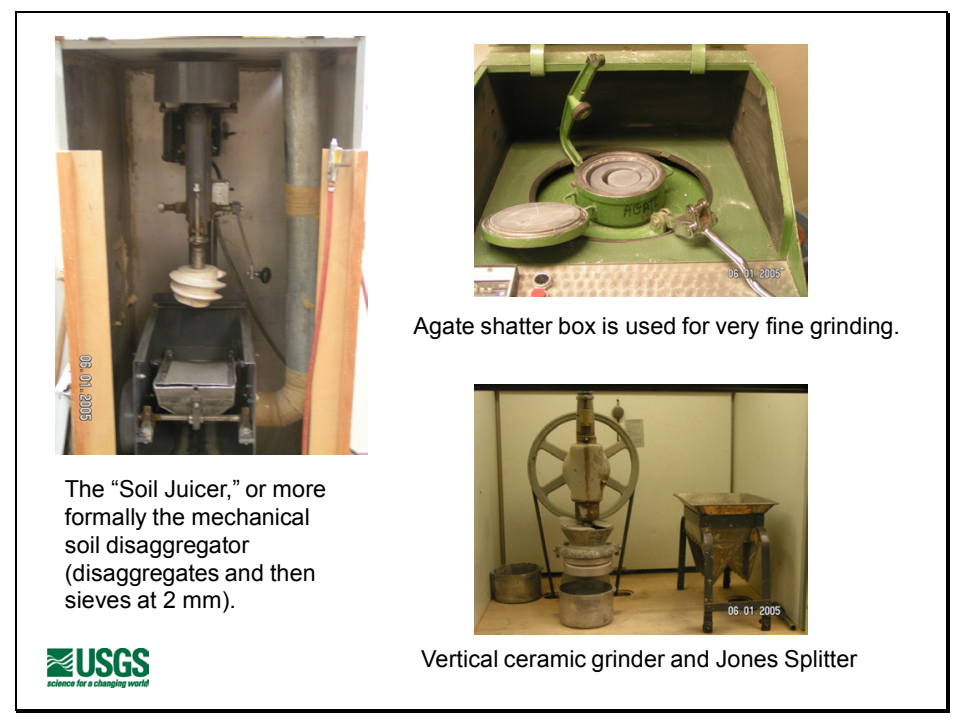

The choice of appropriate sample preparation equipment is the first critical step in the successful analytical scheme. The appropriate care, maintenance, and cleaning of all equipment is critical to the integrity of the analytical sample. For most trace element studies, one should use only high quality agate or ceramic grinding surfaces, especially when trace metals are the focus of the study. This is critical to avoid the possible contamination of the sample with metals. Common contaminants from the use of steel surfaces include $\mathrm{Cr}, \mathrm{Fe}, \mathrm{Ni}, \mathrm{Mo}, \mathrm{REE}$ and Co. Tungsten carbide will contaminate the sample with W, C, and many transition metals. Agate will contaminate with $\mathrm{Si}$, but usually the contamination is lost in the samples' original Si content. This is also true of most ceramic material where the $\mathrm{Si}, \mathrm{Ca}, \mathrm{Al}$, and Na contamination is overpowered by the samples' original content. 
Slide 28

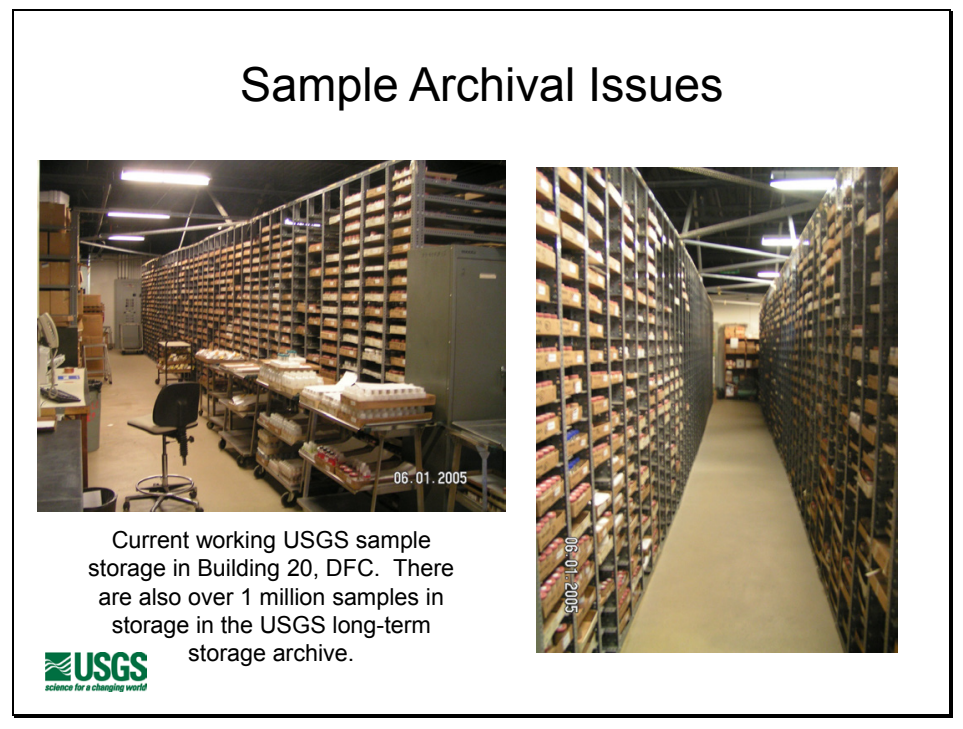

Issues of sample storage for both current and future use of the samples must be addressed. Although cardboard containers are convenient, glass jars with plastic lined metal lids should be used if volatile elements are of a concern, especially for $\mathrm{Hg}$ sample preservation. Cardboard containers do not offer any protection from moisture in humid climates. Common home canning jars of various sizes, ranging from $4 \mathrm{oz}$. up to $64 \mathrm{oz}$., are usually most suitable, such as Mason ${ }^{\circledR}$ or Ball ${ }^{\circledR}$ jars, for long term storage. These types of jars are readily available, lower-cost alternatives to more costly laboratory jars. 
Slide 29

\section{Sample Archival Issues}

- Quantity and availability of material stored.

- Temperature of storage - is freezing required?

- Sample preservation - air-dried only or treatment (sterilization, autoclaving, freezedried, or irradiation).

- Humidity control

- Container material $(\mathrm{Hg}$, volatile analytes, N, S, As, Se forms, organics, biota) - glass with a Teflon $®$ - lined lid is optimal for metal species.

-Where? Who pays? How long (holding times)? ¿USGS 
Slide 30

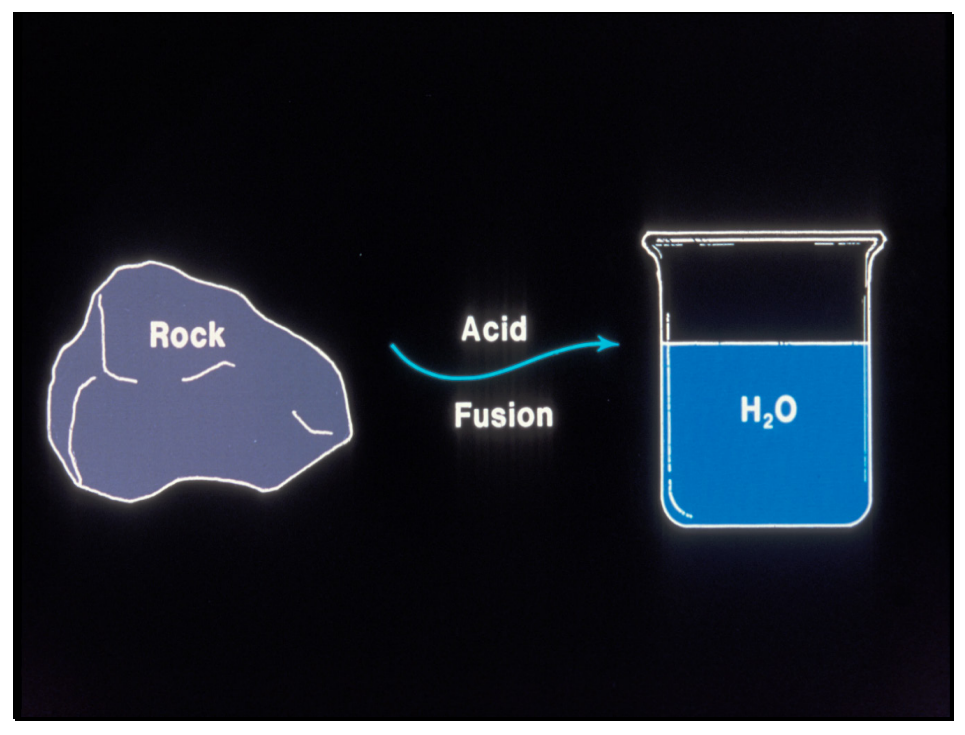

Many analytical schemes require that solid, and even most liquid, samples undergo some type of digestion/pretreatment prior to elemental determination after suitable particle size reduction. For most silicate samples, a digestion usually requires the use of strong mineral acids or alkali fluxes. Most digestions entail elevated temperatures and sometimes elevated pressures. 
Slide 31

\section{Total Digestions}

- Four-acid digestion under reflux conditions - Nitric, hydrofluoric, perchloric, and hydrochloric acids (may still not be total), under various temperature and pressure conditions.

- Alkaline sinter, for example, sodium peroxide

- High temperature fusion, including sodium carbonate and lithium metaborate

- Microwave digestions, with or without hydrofluoric acid

- Aqua regia-especially for sulfide-rich materials-but will not always completely attack silicates. Commonly used by the USEPA and in European labs.

\section{ZUSGS}

There are several good references for choosing the proper method of digestion, which are given in the reference section of this report. Those shown here is a representative selection of the total methods available to the analytical chemist. Each method has its advantages and disadvantages. These include specialty equipment, for example, the required perchloric acid fume hood for the use of perchloric acid or Teflon ${ }^{\circledR}$ digestion vessel when using hydrofluoric acid; analyte volatility; blank contamination; ineffectiveness in dissolving some resistant phases, such as rutile, chromite, cassiterite, corundum, and tourmaline; and exclusion of some analytes, for example, $\mathrm{Li}$ from a lithium metaborate fusion or $\mathrm{Na}$ from a sodium carbonate fusion. 
Slide 32

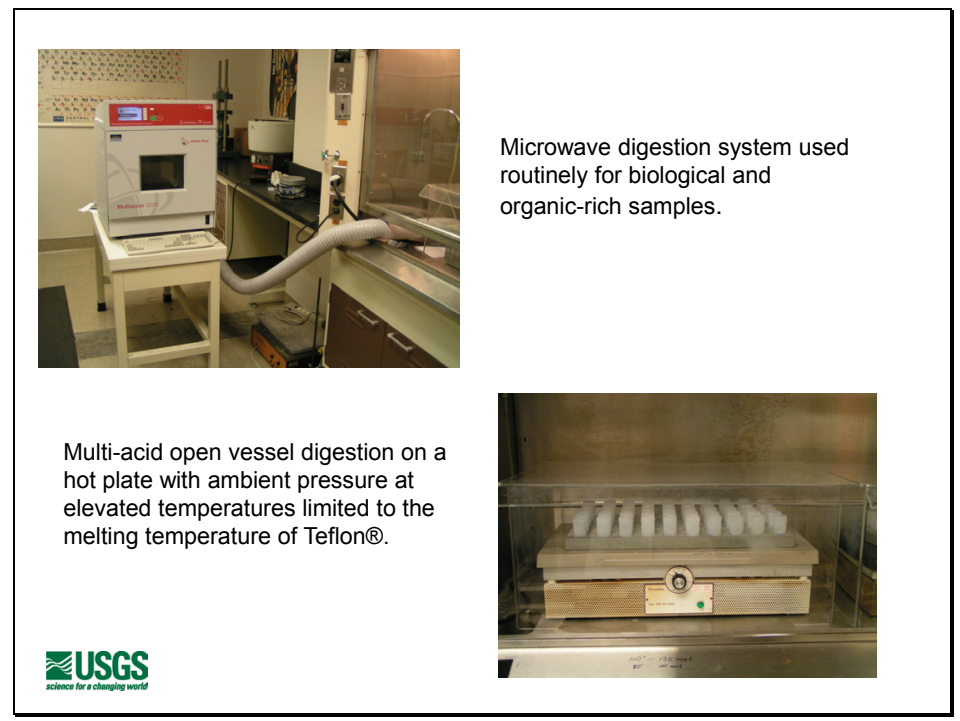


Slide 33

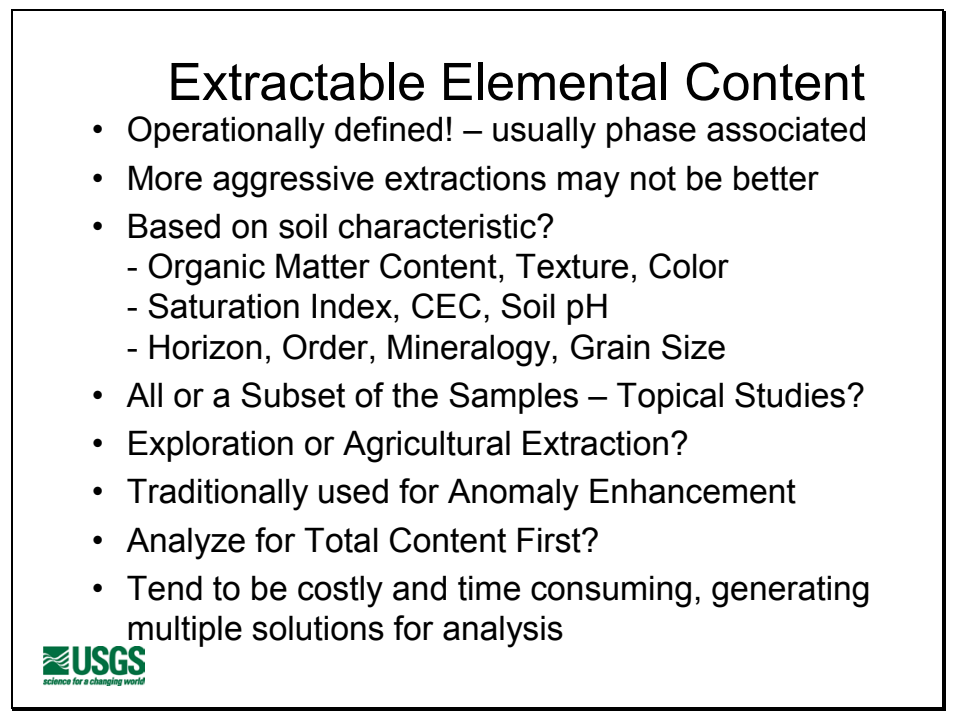

There are many operational variables that affect the amount of the analyte dissolved in a sample. These include the size, shape, and makeup of the digestion vessels; speed and direction of mixing; and the combination and concentration of the extracting solution. Great care must be observed by the analytical chemist to maintain consistency in all aspects of the analytical scheme. 
Slide 34

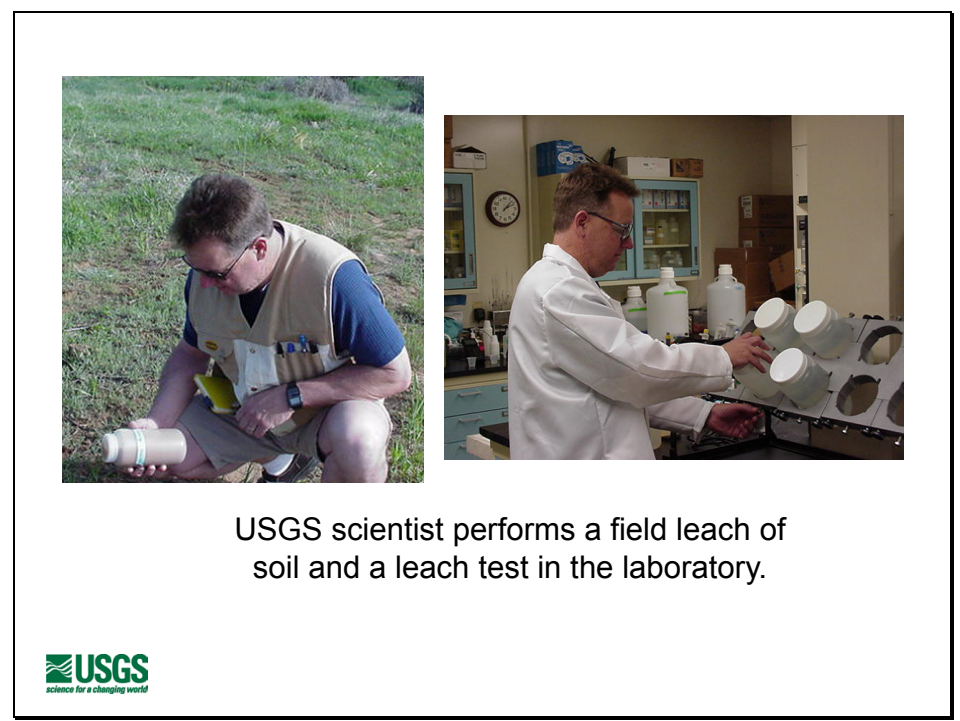

There are both in-field extractions and laboratory extractions. To determine the appropriate extraction, all lies in "What is the Question?" Details of the USGS Field Leach test are given in Hageman (2007b). 
Slide 35

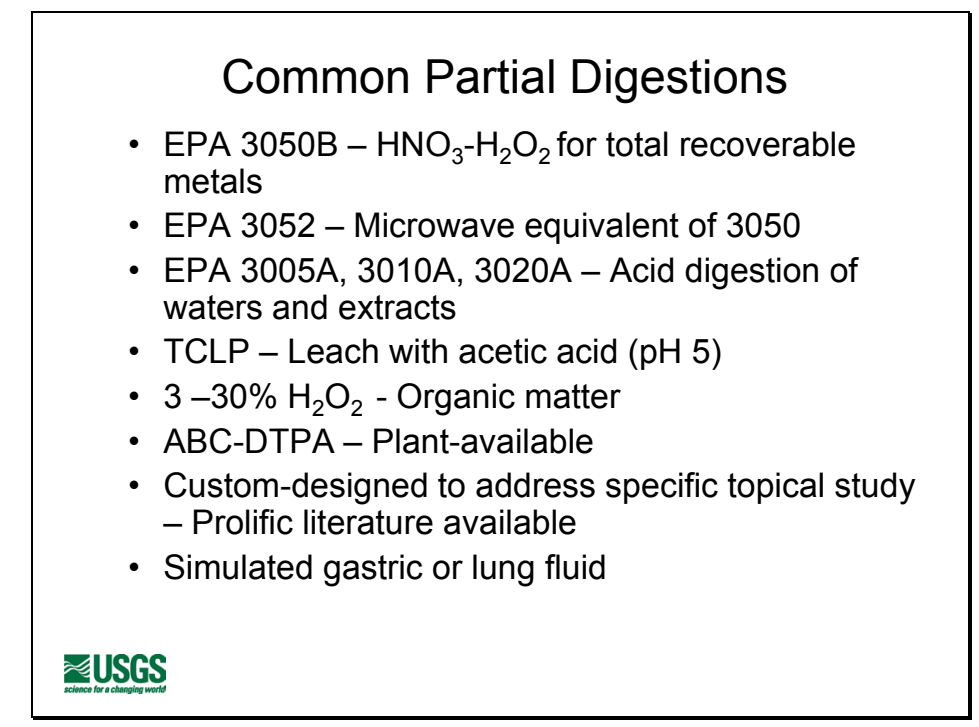

There are a wide variety of partial extractions available to today's scientists. They range from very mild, for example, distilled water extraction, to very aggressive, strongly oxidative acidic $\left(\mathrm{HNO}_{3}\right.$ and $\left.\mathrm{H}_{2} \mathrm{O}_{2}\right)$. Again, knowing the question will determine which extraction or extraction scheme will provide the best information to the scientist.

EPA 3050B: http://www.epa.gov/wastes/hazard/testmethods/sw846/pdfs/3050b.pdf EPA 3052: http://www.epa.gov/waste/hazard/testmethods/sw846/pdfs/3052.pdf EPA 3005A: http://www.epa.gov/waste/hazard/testmethods/sw846/pdfs/3005a.pdf EPA 3010A: http://www.epa.gov/wastes/hazard/testmethods/sw846/pdfs/3010a.pdf EPA 3020A: http://www.epa.gov/waste/hazard/testmethods/sw846/pdfs/3020a.pdf USEPA TCLP (SW-846): "Test Methods for Evaluating Solid Waste, Physical/Chemical Methods", http://www.epa.gov/waste/hazard/testmethods/sw846/index.htm ABC-DTPA: Crock and Severson (1980). 
Slide 36

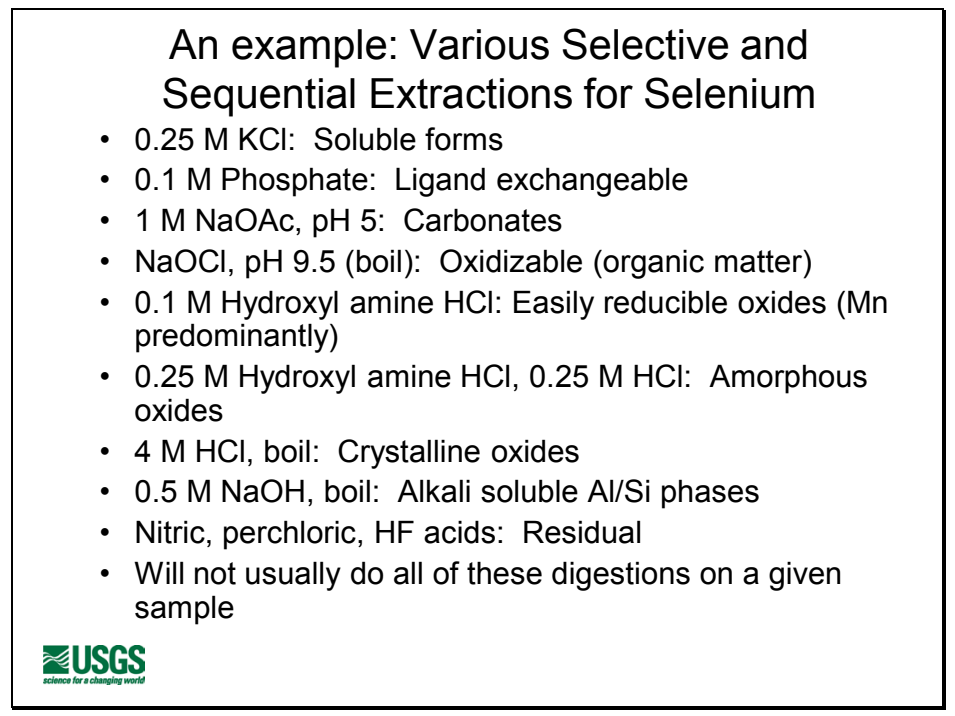

Commonly, extractions are a single digestion, but there are available extraction sequences that will partition analytes into operationally defined phases and occurrences. Chao (1984) describes many partial and sequential extraction schemes commonly used. 
Slide 37

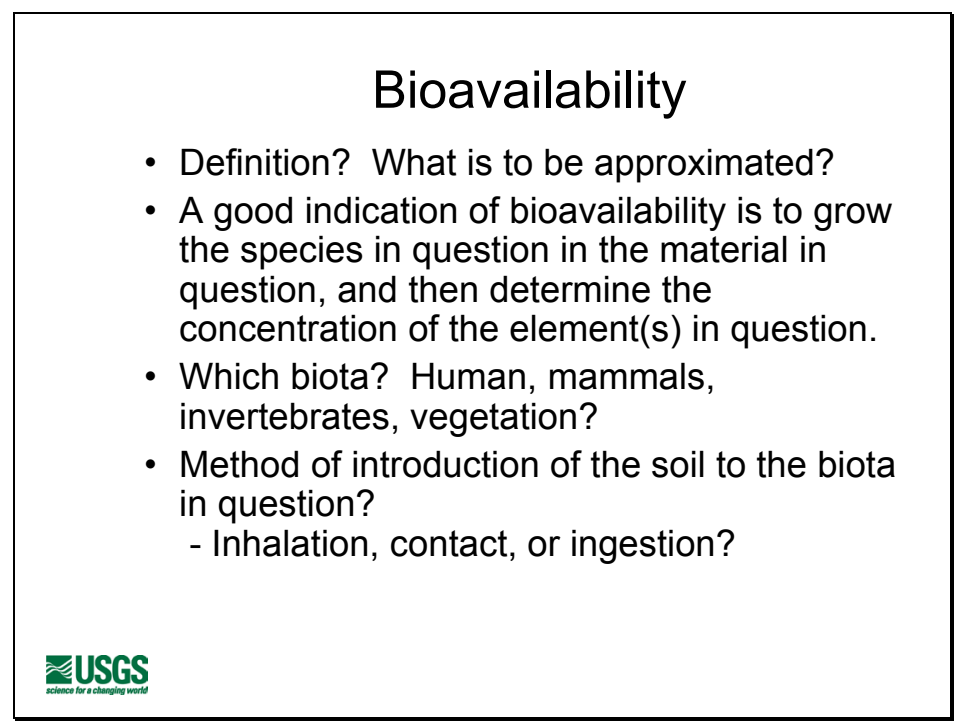

An increasing number of environmental studies are addressing the effects of geological materials on biota. These are typical questions that should be addressed prior to sampling and analysis. An excellent overview summary of bioavailability is presented in Smith and Huyck (1999). 
Slide 38

\section{Bioavailability Measurements}

- Complicated and abundant literature, especially in the medical literature

- Large range of reagent strength, composition, temperature

- Biota whole tissue

- Simple water extraction

- Weak to strong acids

- Simulated lung fluid or gastric juice 
Slide 39

\begin{tabular}{|c|c|c|c|c|}
\hline \multicolumn{5}{|c|}{$\begin{array}{c}\text { Concentrations and ranges }(\mathrm{mg} / \mathrm{Kg}) \text { for selected } \\
\text { trace elements in U.S. soils }\end{array}$} \\
\hline & Average & $\begin{array}{l}\text { U.S. Soils, } \\
\text { Range }\end{array}$ & \begin{tabular}{|c|} 
Western \\
U.S., grand \\
mean
\end{tabular} & $\begin{array}{l}\text { Eastern } \\
\text { U.S., grand } \\
\text { mean }\end{array}$ \\
\hline As & 5 & $<0.1-97$ & 5.5 & 4.8 \\
\hline $\mathrm{Cu}$ & 30 & $<1-700$ & 21 & 13 \\
\hline $\mathrm{Hg}$ & 0.03 & $<0.01-4.6$ & 0.046 & 0.081 \\
\hline $\mathrm{Pb}$ & 10 & $<10-700$ & 17 & 14 \\
\hline Mo & 2 & $<1-15$ & 0.85 & 0.32 \\
\hline $\mathrm{Se}$ & 0.3 & $<0.1-4.3$ & 0.23 & 0.30 \\
\hline $\mathrm{Zn}$ & 50 & $<5-2900$ & 55 & 40 \\
\hline
\end{tabular}

This chart is taken from Smith, K.S. and Huyck, H.L. (1999). This chart demonstrates the natural wide-concentration range for several important elements in soil studies. The analytical method of detection must be robust enough to provide a sufficiently large enough analytical reporting range to accommodate this large natural variation. When soils are affected by anthropogenic sources, this robust nature becomes even more important. 


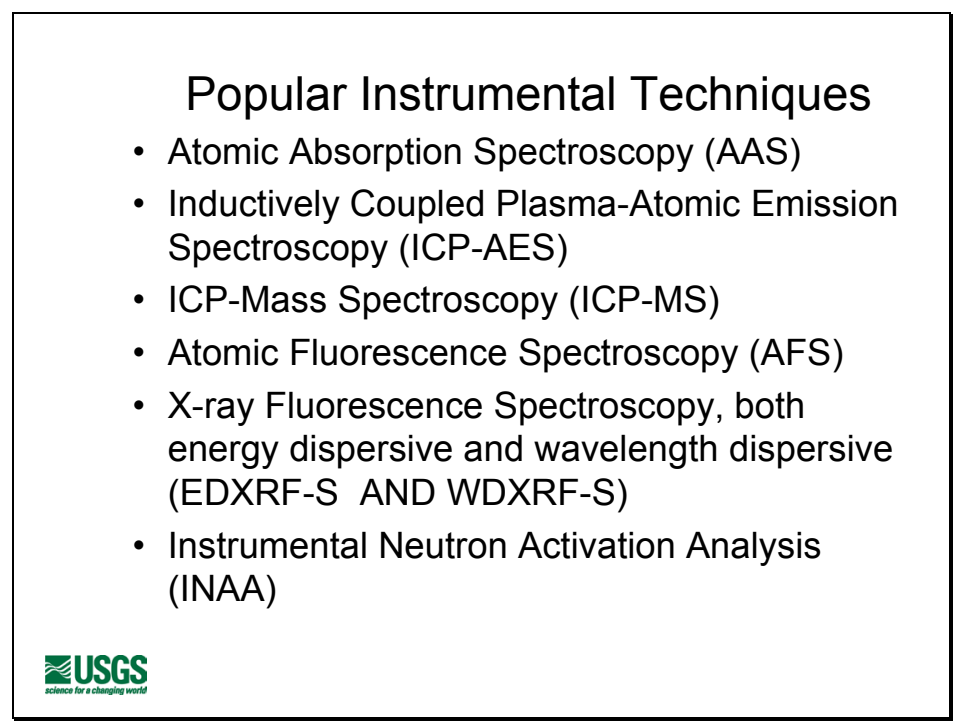

These are some of the common analytical spectroscopic methods available to the analytical chemist for both routine and research methods. The bottom line in any study is for the method of analysis to provide high quality, quantifiable data. If a technique provides data at the "less than" or "not detectable" level for the majority—or, in some cases, even one sample — the data set loses value as a scientific tool. The analytical technique chosen must provide both accurate and precise data at or preferably below the "action level" of a study. So if one were to choose AAS and get only "ND" or < data, an alternative technique must be used. A classical reference for instrumental analysis is Skoog and others (2006). 
Slide 41

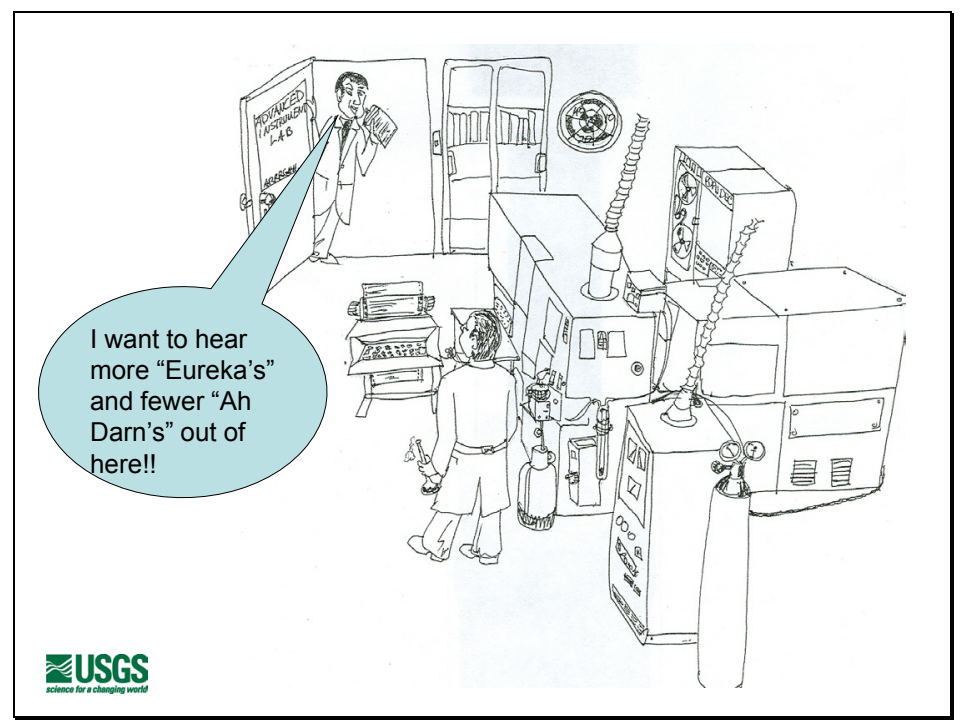

Original cartoon by David L. Fey (USGS, Denver, CO).

Modern instrumentation can be very complex and technically challenging to operate and keep at peak performance. This is especially true when dealing with complex matrices common to the analyses of geological and environmental materials. The trends in instrumental methods are to be multi-elemental, either sequential or simultaneous in determination of a diverse group of elements. The prevalent demands are for more and more elements quantified at lower and lower concentration levels, often ranging into the sub $-\mu \mathrm{g} / \mathrm{Kg}$ level in the sample and even lower in the sample digestate - often more than 100 fold less due to dilution. 
Slide 42

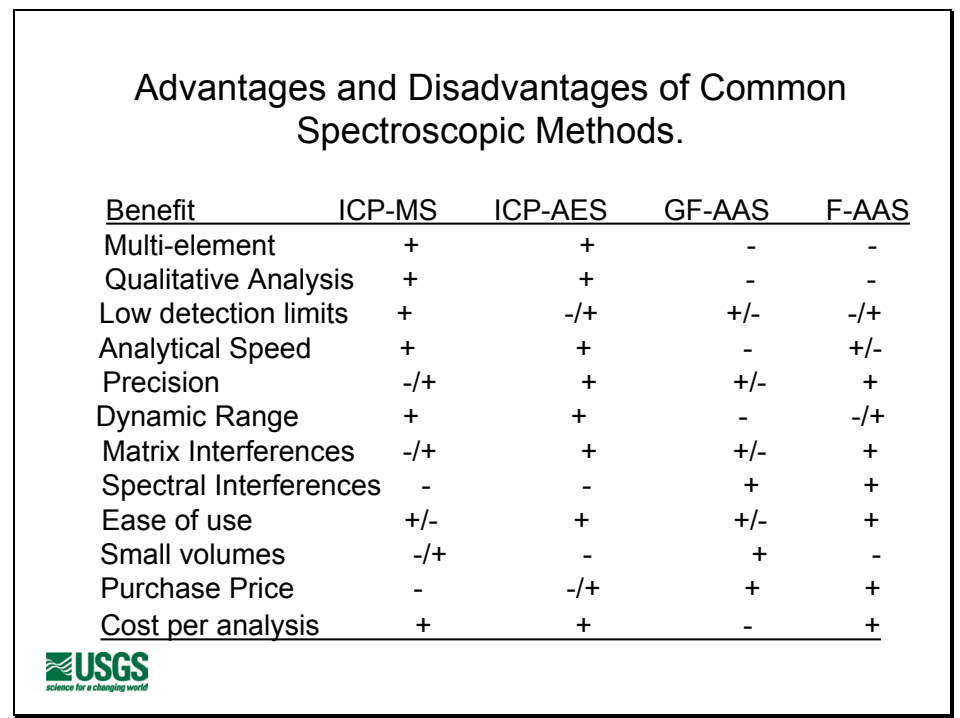

A + would mean this benefit would be a relative advantage for this method, a - would be a disadvantage, and a $+/$ - could mean an advantage or disadvantage, depending on the sample and digestion solution matrix and the analyte of concern. A technique must be chosen that will provide enough sensitivity to obtain quantifiable data for the analytes of interest for most, if not all, samples in a study. 


\begin{tabular}{|c|c|c|c|c|c|}
\hline \multicolumn{6}{|c|}{$\begin{array}{l}\text { Atomic Spectroscopy detection limits }(\mu \mathrm{g} / \mathrm{L} \text { in } \\
\text { solution) - single element }\end{array}$} \\
\hline & $\begin{array}{c}\text { Flame } \\
\text { AAS }\end{array}$ & $\begin{array}{l}\text { HGA- } \\
\text { AAS }\end{array}$ & $\begin{array}{l}\text { ICP- } \\
\text { AES }\end{array}$ & $\begin{array}{l}\text { ICP- } \\
\text { MS }\end{array}$ & $\begin{array}{c}\text { Hydride } \\
\text {-AAS }\end{array}$ \\
\hline As & 150 & 0.5 & 30 & 0.13 & 0.03 \\
\hline $\mathrm{Cu}$ & 1.5 & 0.25 & 1.5 & 0.003 & -- \\
\hline $\mathrm{Hg}$ & 300 & 1.5 & 30 & 0.004 & 0.009 \\
\hline $\mathrm{Pb}$ & 15 & 0.15 & 30 & 0.001 & -- \\
\hline Mo & 45 & 0.2 & 7.5 & 0.003 & -- \\
\hline $\mathrm{Se}$ & 100 & 0.7 & 90 & 0.08 & 0.03 \\
\hline $\mathrm{Zn}$ & 15 & 0.3 & 1.5 & 0.003 & -- \\
\hline \multicolumn{6}{|l|}{$\approx$ USGS } \\
\hline
\end{tabular}

The determination of $\mathrm{Hg}$ is usually performed using cold vapor (CV) AAS or atomic fluorescence spectroscopy (AFS) methodologies, usually with stannous chloride as the reductant. Sodium borohydride has been reported in the literature for the reductant, but is not commonly used because the background is very noisy. When $\mathrm{Hg}$ is determined by AFS, picogram/gram concentrations are routinely quantified. Crock (1996) gives an overview of $\mathrm{Hg}$ analysis in soils. Hageman (2007a) presents a CV-AFS method for $\mathrm{Hg}$ in soil. 
Slide 44

\section{Atomic Absorption Spectroscopy}

- Flame AAS, different flames

- Graphite furnace AAS, single and multi-channel, platform or tube vaporization

- Hydride generation, continuous flow and flow injection

- Different background correction methods

- Cold-Vapor AAS for Hg determination

- Abundant application literature and is time-tested and proven for more than 50 years

\section{¿USGS}

Atomic absorption spectrometry (AAS) became the backbone of many of the environmental and geochemical laboratories by the mid-1970s and continues today to be a very important technique for the determination of many environmentally important elements. Among the reasons for AAS popularity are its relative low purchase price and maintenance cost, abundant literature and applications, acceptance by many regulatory agencies, capability of determining about 70 elements, sensitivity and detection limits that satisfy many studies, speed of analysis, relative freedom from interferences, reasonable precision and accuracy, simplicity, and its field portability. But AAS also has its limitations. AAS is not useful for determining nonmetals, such as sulfur, or refractory elements at useful levels. AAS also tends to be a sequential method of analysis. Simultaneous multielement AAS determinations have not yet proven to be practical on a routine basis for more than a few elements.

AAS has been subdivided into four main categories. These categories are based on the method of sample introduction and the absorption cell. These include flame - AAS (F-AAS), graphite furnace - AAS (GF-AAS), hydride generation - AAS (HG-AAS), both continuous flow and flow injection HG-AAS, and cold vapor-AAS (CV-AAS). F-AAS has seen great application over the years as the method of choice for trace element analysis, replacing many of the colorimetric methods. A sample is first dissolved, diluted to an appropriate concentration level, and then aspirated into the flame of the AAS instrument. F-AAS is simple to perform and has few spectral interferences and minimal chemical interferences. However, F-AAS is not always sensitive enough for the levels of analytes found in environmental samples. 


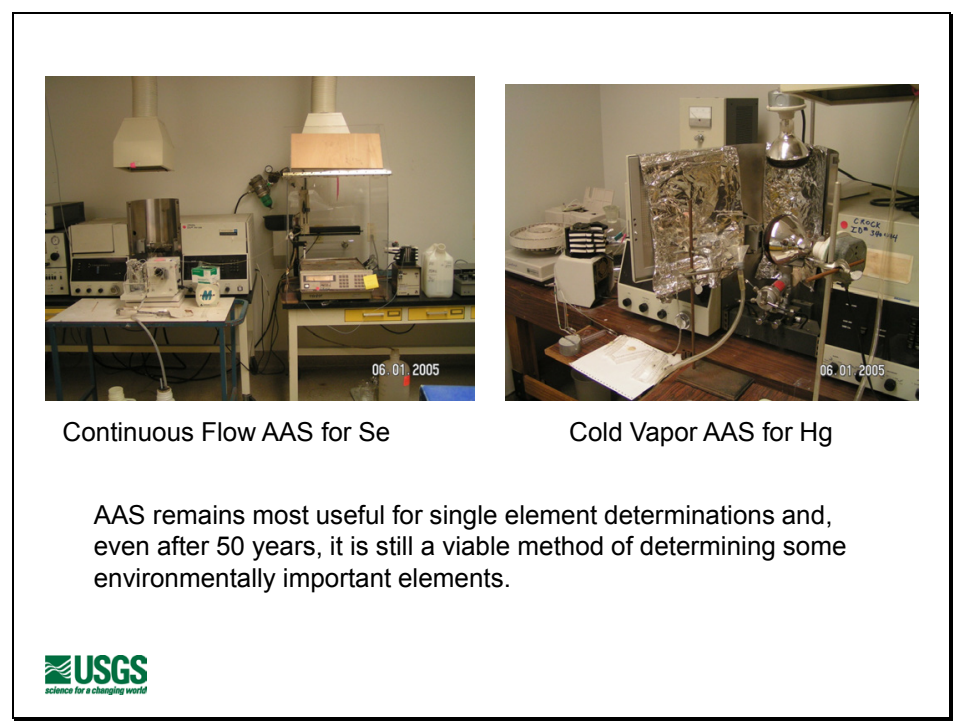

AAS notes continued:

For a comparison of detection limits between the four common spectroscopic techniques, consult table 1 in the text of this report. To increase sensitivity and to make the analysis of small volumes possible, GF-AAS was developed. Here the flame has been replaced with a heated graphite tube, and the sample is injected into this tube for a more complete and efficient atomization of the sample. GF-AAS, however, tends to be a tedious, slow method. It also suffers from more chemical and spectral interferences, often giving the illusion that GF-AAS is to be considered more art than science.

For the hydride-forming elements - such as $\mathrm{As}, \mathrm{Sb}, \mathrm{Se}, \mathrm{Bi}, \mathrm{Sn}$, and $\mathrm{Pb}$ - the introduction of continuous flow HG-AAS offered a reduction in both chemical and spectral interferences while offering increased automation with the sensitivities of the GF-ASS methods (for example, Crock, 1986; Crock and Lichte, 1982). In general, for HG-AAS methods an acidic digest of the sample is mixed with pre-reducing and/or complexing reagents, it is then reduced to form the gaseous hydride of the analyte of concern (usually with sodium borohydride), the gaseous phases are subsequently separated from the liquid phases, and, finally, the gases are decomposed in a heated quartz cell in the path of an AAS spectrometer. HG-AAS methods tend to be the favored method of analysis for $\mathrm{As}, \mathrm{Sb}$, and $\mathrm{Se}$ in environmental samples due to their lower detection limits and relative freedom from interferences. 


\section{AAS Advantages and Limitations}

- Low purchase and maintenance costs

- Widespread use with abundant time-tested methods and well-defined interferences

- Acceptance by regulatory agencies

- Reasonable sensitivity and accuracy/precision

- Simplicity and field portable

- Sequential determination, speed of analysis

\section{ZUSGS}

AAS notes continued: CV-AAS remains the chosen method of analysis for mercury in most matrices. Over the years, many modifications have been made to this method, but it still remains the method of choice for environmental samples. The latest innovations in the determination of mercury in environmental samples have focused on using atomic fluorescence as the method of detection after standard digestion and separation procedures. Mercury both absorbs and fluoresces at $254 \mathrm{~nm}$. Atomic fluorescence inherently has a much larger dynamic analytical range and tends to be at least two orders of magnitude more sensitive than the CV-AAS method. Cold vaporatomic fluorescence spectrometry (CV-AFS) offers the ability to determine mercury at or below the part per trillion levels (ng/L) in water. CV-AFS tends to be relatively interference free when compared to the CV-AAS method, but the analyst must be very careful of sample contamination and reagent purity. CV-AFS is steadily gaining popularity as the method of choice for $\mathrm{Hg}$ determinations. Also, gaining acceptance is thermal sample decomposition and subsequent determination by AAS or AFS. This method has the distinct advantage of no sample preparation and thus no $\mathrm{Hg}$ loss due to the digestion procedure. 


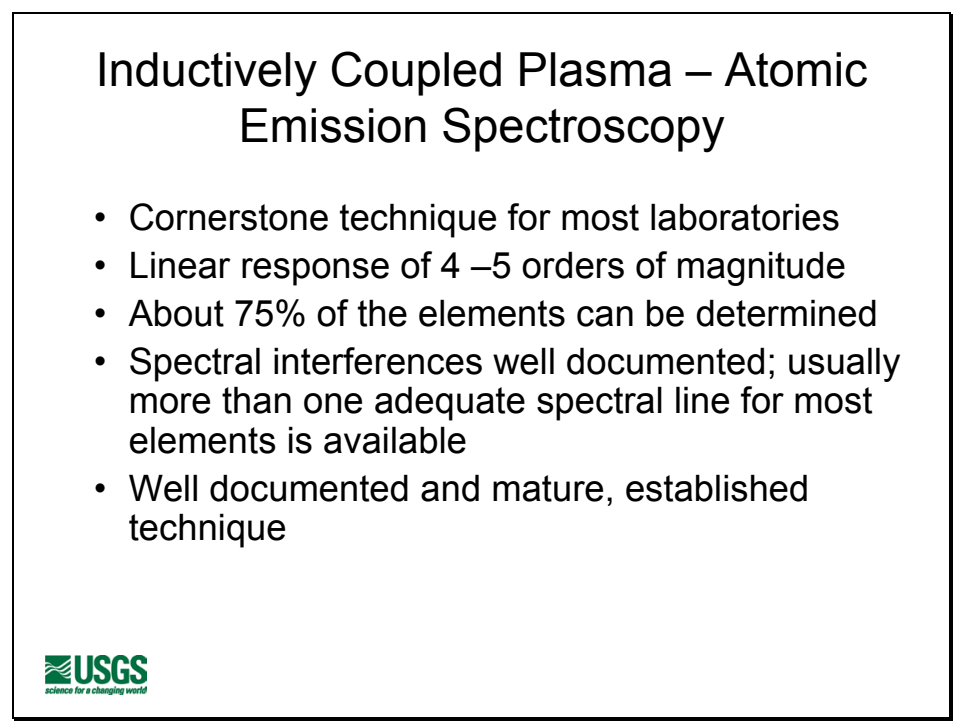

ICP-AES has also become a very popular and trusted multi-element method complimentary to AAS, especially graphite furnace and hydride generation methods. Since its introduction in the early 1970s, inductively coupled plasma-atomic emission spectroscopy (ICP-AES) has become an important technique for the analysis of environmental and geochemical materials for their trace, minor, and major elemental content. About three-fourths of the common elements can be determined by this technique, with lower limits of detection in the range of 0.05 to $50 \mu \mathrm{g} / \mathrm{L}$. This technique is noted for linearity of response, often covering four to five orders of magnitude, and relative freedom from matrix effects that often plague other spectroscopic and classical methods. Another advantage is that the analyte solution can contain high total dissolved salts. The technique offers excellent measurement precision, usually from 1 to 3 percent relative standard deviation, and has good accuracy. ICP-AES is a rapid multi-element technique, by which 30 to 40 elements can be determined routinely within two to three minutes.

However, ICP-AES is subject to spectral interferences, background shifts, and matrix effects. An internal standard, for example, lutetium, can be used to help minimize these problems. Inter-element correction factors and background corrections are applied routinely. Further corrections are made when an element influences other elements beyond the "normal correction." It is common to not report an element due to the extraordinary interference of an interfering element. Proper matching of standard and sample matrices can generally negate matrix effects. Modern ICP-AES systems generally come in one of two types: radially-viewed plasma or axially-viewed plasma. Radially-viewed systems have detection limits ranging from 0.2 to 100 $\mu \mathrm{g} / \mathrm{L}$ (depending on the element), and upper linear ranges as high as $1000 \mathrm{mg} / \mathrm{L}$. Axially-viewed systems provide lower detection limits by roughly a factor of ten $(0.03-10 \mu \mathrm{g} / \mathrm{L})$; however, there is also a ten-fold reduction in the upper linear range to around $100 \mathrm{mg} / \mathrm{L}$ for most elements. Some systems allow both radial and axial viewing on the same system, and this has some advantages where the analytical goal is to improve detection limits, while maintaining the high upper linear range ICP-AES is known for. A survey of major ICP-AES instrumentation suppliers, including Thermo, Varian (recently purchased by Agilent), and PerkinElmer shows that only Thermo (ICAP 
6000 Series) and PerkinElmer (Optima 7000 DV series) offer ICP-AES instruments capable of performing axial or radial viewing in the same instrument. The Varian instruments are provided in a fixed axial-only or radial-only configuration. During instrument evaluation, laboratory management should decide which elements, and the required detection limits and linear ranges of said elements, they want to determine by ICP-AES. This would help to narrow the choice of instrument and ensure that an instrument is obtained that will fulfill their needs. Based the USGS's experience with the relatively complex nature of geochemical samples and the resulting solutions from total rock digestions, it is recommended that laboratory management consider ICP-AES instruments that provide some type of spectral deconvolution software to correct for spectral overlaps and interferences, rather than an instrument that uses the traditional Interfering Element Correction (IEC) method. Both the Varian (720/730-ES) system and the PerkinElmer (Optima 7000 DV Series) offer spectral deconvolution capabilities. The Varian Fast Automated CurveFitting (FACT) software provides spectral deconvolution capabilities as does the Multi-component Spectral Fitting (MSF) software on the PerkinElmer systems. The systems currently offered by Thermo (ICAP 6000 Series) only offer traditional IEC corrections where each interfering element is run to determine the apparent signal on the analyte of interest, and then a ratio of analyte to interfering element signal intensities is used to subtract the interference away from the analyte signal. The limitation is that this method cannot easily correct for the possibility that more than one interfering element is acting upon an element of interest at the same time or that the interference might not be linear with an increase in the concentration of the interfering element. At the USGS, we have found the spectral deconvolution software provides much more accurate results in complex geochemical matrices.

ICP-AES instruments can be obtained in a simultaneous or sequential optical configuration. It is recommended that laboratory management consider simultaneous ICP-AES systems that can determine a large number of elements simultaneously using a single solid-state "chip" detector or multiple photomultiplier detectors rather than a sequential configuration where each element is determined separately using a single photomultiplier detector. Since most modern ICP-AES systems have solid-state ("chip") detectors of some type, an evaluation should be done that all of the elements of interest are covered on the detector chip for the instrument selected or that more than one line exists for elements that are often found in a wide range of concentrations. For example, one limitation of the PerkinElmer Optima ICP-AES is that there are no lines for iridium on the chip. This is an important limitation for labs where iridium is an element of interest. Evaluations should also be performed such that signals from elements typically high in a laboratory's samples do not "bloom" over into adjacent pixels on the chip for other elements of interest or that the detector chip provides some type of anti-blooming protection circuitry. Blooming has become less of an issue as this type of detector technology has evolved.

Finally, applications and service support is a critical feature in the selection of an ICP-AES system that should not be overlooked. Laboratory management should evaluate the number and experience of the instrument vendor applications and service personnel that support their geographic area. The availability of parts and service should the instrument need to be repaired is of utmost importance, particularly if there is no backup analytical method or instrumentation in place. 
Slide 48

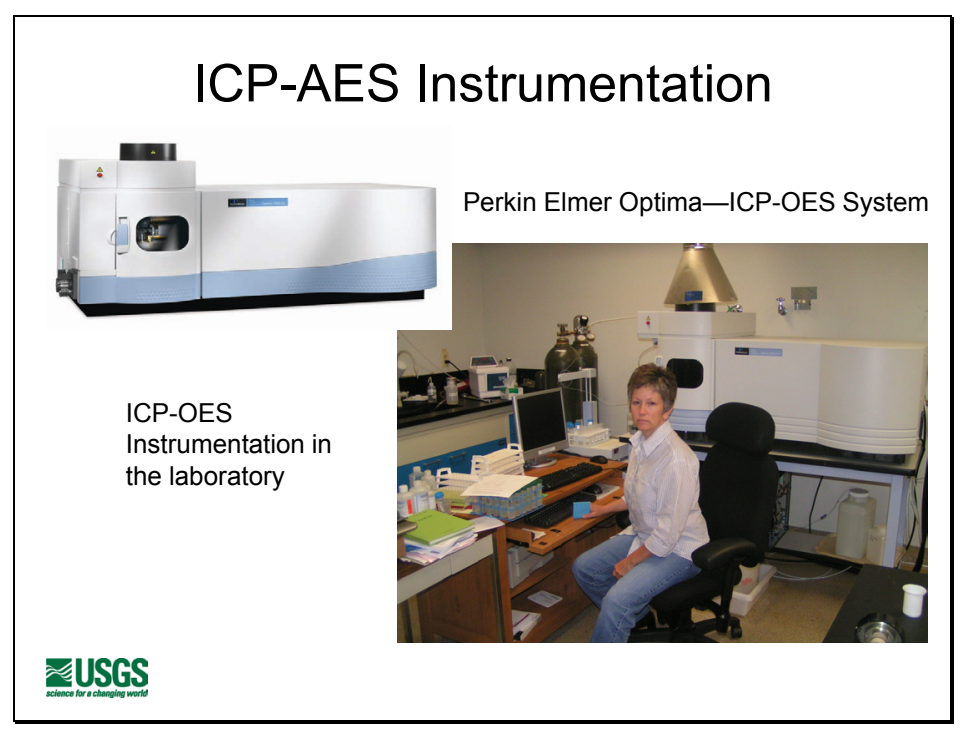

USGS reporting limits/range for 40 elements by ICP-AES after an acid digestion

$\begin{array}{llllll}\mathrm{Al} & 0.005 & 50 \% & \mathrm{Ga} & 4 & 50,000 \mathrm{mg} / \mathrm{kg} \\ \mathrm{Ca} & 0.005 & 50 \% & \mathrm{Ho} & 4 & 5,000 \mathrm{mg} / \mathrm{kg} \\ \mathrm{Fe} & 0.02 & 25 \% & \mathrm{La} & 2 & 50,000 \mathrm{mg} / \mathrm{kg} \\ \mathrm{K} & 0.01 & 50 \% & \mathrm{Li} & 2 & 50,000 \mathrm{mg} / \mathrm{kg} \\ \mathrm{Mg} & 0.005 & 5 \% & \mathrm{Mn} & 4 & 50,000 \mathrm{mg} / \mathrm{kg} \\ \mathrm{Na} & 0.006 & 50 \% & \mathrm{Mo} & 2 & 50,000 \mathrm{mg} / \mathrm{kg} \\ \mathrm{P} & 0.005 & 50 \% & \mathrm{Nb} & 4 & 50,000 \mathrm{mg} / \mathrm{kg} \\ \mathrm{Ti} & 0.005 & 25 \% & \mathrm{Nd} & 9 & 50,000 \mathrm{mg} / \mathrm{kg} \\ \mathrm{Ag} & 2 & 10,000 \mathrm{mg} / \mathrm{kg} & \mathrm{Ni} & 3 & 50,000 \mathrm{mg} / \mathrm{kg} \\ \mathrm{As} & 10 & 50,000 \mathrm{mg} / \mathrm{kg} & \mathrm{Pb} & 4 & 50,000 \mathrm{mg} / \mathrm{kg} \\ \mathrm{Au} & 8 & 50,000 \mathrm{mg} / \mathrm{kg} & \mathrm{Sc} & 2 & 50,000 \mathrm{mg} / \mathrm{kg} \\ \mathrm{Ba} & 1 & 35,000 \mathrm{mg} / \mathrm{kg} & \mathrm{Sn} & 5 & 50,000 \mathrm{mg} / \mathrm{kg} \\ \mathrm{Be} & 1 & 5,000 \mathrm{mg} / \mathrm{kg} & \mathrm{Sr} & 2 & 15,000 \mathrm{mg} / \mathrm{kg} \\ \mathrm{Bi} & 10 & 50,000 \mathrm{mg} / \mathrm{kg} & \mathrm{Ta} & 40 & 50,000 \mathrm{mg} / \mathrm{kg} \\ \mathrm{Cd} & 2 & 25,000 \mathrm{mg} / \mathrm{kg} & \mathrm{Th} & 6 & 50,000 \mathrm{mg} / \mathrm{kg} \\ \mathrm{Ce} & 5 & 50,000 \mathrm{mg} / \mathrm{kg} & \mathrm{U} & 100 & 100,000 \mathrm{mg} / \mathrm{kg} \\ \mathrm{Co} & 2 & 25,000 \mathrm{mg} / \mathrm{kg} & \mathrm{V} & 2 & 30,000 \mathrm{mg} / \mathrm{kg} \\ \mathrm{Cr} & 2 & 50,000 \mathrm{mg} / \mathrm{kg} & \mathrm{Y} & 2 & 25,000 \mathrm{mg} / \mathrm{kg} \\ \mathrm{Cu} & 2 & 15,000 \mathrm{mg} / \mathrm{kg} & \mathrm{Yb} & 1 & 5,000 \mathrm{mg} / \mathrm{kg} \\ \mathrm{Eu} & 2 & 5,000 \mathrm{mg} / \mathrm{kg} & \mathrm{Zn} & 2 & 15,000 \mathrm{mg} / \mathrm{kg}\end{array}$


Slide 49

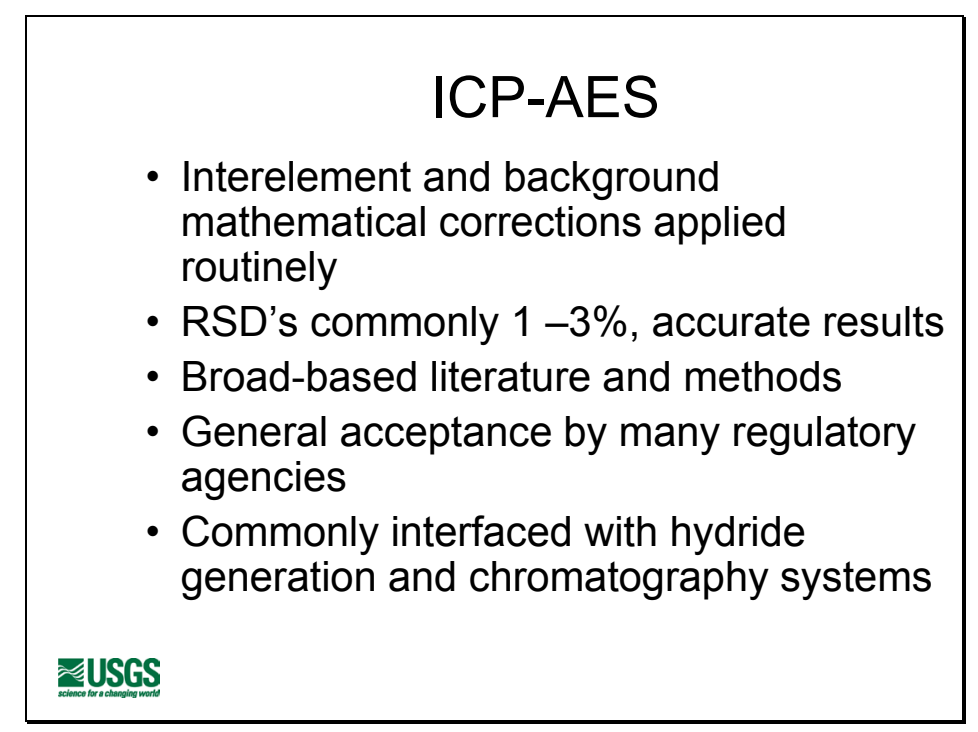

Relative standard deviation (RSD) is a measure of the precision of the method. Good precision does not imply good accuracy. One can measure the wrong value quite precisely and still be wrong. Accuracy is a measure of how close the reported value is to the hypothetical "true" value. Many of the problems with ICP-AES determinations have been defined and can be corrected for, thus contributing to a more accurate determination. 
Slide 50

\section{ICP-AES}

- Internal standards are very useful; for example, Lu for background, matrix, and drift problems

- Axial and radial views of the plasma for optimum performance

- Multielement, simultaneous, or sequential analyses

- Very cost-effective technique with high sample throughout 
Slide 51

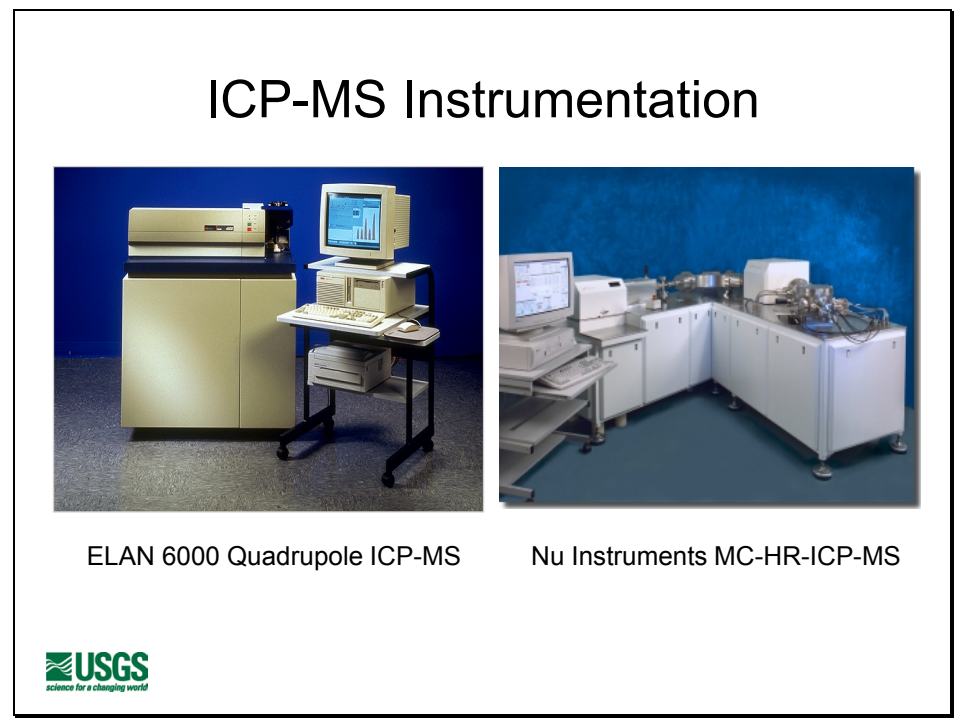

ICP-MS instrumentation is also complimentary to other spectroscopic methods, offering a wide detection range for much of the periodic table at sufficiently small limits of determination to be useful for many investigations. 
Slide 52

\section{Inductively Coupled Plasma - Mass Spectrometry}

- Ability to measure isotope abundances of most elements between mass 6 (Li) and mass $238(\mathrm{U})$.

- Many elements have at least one isotope free of isobaric interferences.

- Few molecular interferences and these are well known.

- Commonly $7-8$ orders of magnitude analytical range (sub ppb - x00 ppm).

\section{FUSGS}


Slide 53

\section{ICP-MS Quantitative Analysis}

- Direct aspiration of digested material

- Gas introduction; for example, hydride generation or cold vapor

- Direct solid analysis by slurry nebulization, laser ablation, arc or spark ablation, or direct sample insertion into the plasma

- Chromatographic speciation analysis

- Isotope analysis

₹USGS 
Slide 54

\section{Plasma-Spectrometer Interface}

- Cones (orifices) will collect a deposit of Al, $\mathrm{Ca}$, and $\mathrm{Mg}$ oxides when rock/soil digests are analyzed. Need to be cleaned daily.

- ICP-MS will show intensity drift as cones become dirty. Need to precondition cones at start of day by running the sample matrix for a period of time before calibration.

ZUSGS

As with most instruments, there are unique problems with digested geological materials, usually from concomitant elements and high dissolved contents of the analytical solution. 


\section{Detectors}

- Large changes in ion counts require use of dual detectors (pulse and analog).

- Dual detector response needs to be calibrated weekly (we do it daily and is manufacturer specific). Must check each mass to be measured in samples (do not forget to do interfering elements as well).

- Detectors will wear out and will need to be replaced every 6 - 18 months, depending on usage and sample concentration 
Slide 56

\section{Benefits of ICP-MS}

- Rapid multi-element analysis

- Very low detection limits

- Isotopic analysis ( isotope dilution quantitation is accurate and cheap )

- Spectral simplicity for mass $>84$ (must be careful at masses $<84$ due to molecular interferences)

- The REEs have many interference issues and many can be overcome with proper isotope selection and correction for molecular, usually oxide, interferences

\section{₹USGS}




\section{Nebulizers}

- Clogging is a concern, so filter samples if precipitates are observed (just like ICPAES)

- For routine operation, flow rate must be optimized to keep $\mathrm{CeO} / \mathrm{Ce}$ ratio below 0.03 (high flow rate is good for sensitivity but bad for oxide interferences) or lower for REE analyses. With special aerosol desolvation systems, the $\mathrm{CeO} / \mathrm{Ce}$ can be reduced to $<0.5 \%$. 
Slide 58

\section{Peristaltic Pump}

- Ensures constant flow rate to nebulizer

- Corrects for differences in viscosity of samples and standards

- Can be used to add internal standard solution to each sample on-line 
Slide 59

\section{Internal Standards}

- Must be an element NOT in the samples

- MUST use internal standards to correct for drift

- Need several to cover mass range. Ratio element to internal standard that is $+/-50$ mass units away

- Must be similar in the $1^{\text {st }}$ ionization potential

- Can be added to each sample or can be added on-line by combining 2 flows

- We use a solution of $500 \mathrm{ppb}{ }^{6} \mathrm{Li}, 20 \mathrm{ppb}$ Rh, $10 \mathrm{ppb}$ Ir

- In, Lu, Tb, Ho, and Bi are commonly used

- Sc is acceptable for water, but not for rocks or soils 
Slide 60

\section{Element Mass Recommendations}

- The most abundant isotope is not always the best choice

- Be aware of molecular ion interferences combinations of $\mathrm{Ar}, \mathrm{O}, \mathrm{H}, \mathrm{Cl}, \mathrm{C}, \mathrm{REE}$ oxides

\section{₹USGS}

An in depth study of polyatomic interferences in ICP-MS is presented by May and Wiedmeyer (1998). 
Slide 61

\section{Calibration}

- Can use either solution standards or digests of rock standards for rock/soil work. We prefer rock digests because of matrix match; however, this can introduce sample preparation bias into the calibration curve. We are currently investigating changing to aqueous standards for calibration.

- For water analyses, best to use a combination of solution standards and natural water standards.

- For vegetation, we calibrate with solution standards and ashed, digested NIST plant standards.

\section{₹USGS}




\section{Daily Performance Check}

- After calibration, good idea to run the same instrument check solution each day. Helps to spot instrument problems if changes are seen from one day to the next.

- We use a solution containing $10 \mathrm{ppb}$ of: $\mathrm{Ba}, \mathrm{Cd}, \mathrm{Ce}, \mathrm{Cu}, \mathrm{Mg}, \mathrm{Rh}, \mathrm{Pb}, \mathrm{U}$ in $2 \% \mathrm{HNO}_{3}$

- Use the solution as recommended by the instrument manufacturer

\section{₹USGS}


Slide 63

\section{Interferences - Isobaric}

- ${ }^{35} \mathrm{Cl}$ and ${ }^{37} \mathrm{Cl}$ form molecular ions that interfere with many elements

- $\mathrm{ArCl}$ on ${ }^{75} \mathrm{As} \quad 40+35=75$

As $=$ As75 $-\left(3.127^{*}\left(\operatorname{Se} 77-0.874^{*} \mathrm{Se} 82\right)\right)$

$=$ As $75-3.127^{*} \mathrm{Se} 77+2.733^{*} \mathrm{Se} 82$

where As75 = signal at mass 75 in counts $/$ sec

Se77 = signal at mass 77 in counts $/ \mathrm{sec}$

Se82 $=$ signal at mass 82 in counts $/ \mathrm{sec}$

- $\mathrm{ClO}$ on ${ }^{51 \mathrm{~V}} \quad 35+16=51$

Avoid using $\mathrm{HCl}$ for ICP-MS work whenever possible, especially if $\mathrm{As}, \mathrm{Se}$, or $\mathrm{Cr}$ are analytes of interest. Use $\mathrm{HNO}_{3}$.

\section{EUSG}


Slide 64

\section{Interferences}

High sulfur matrices:

$\mathrm{SO}$ on ${ }^{48} \mathrm{Ti} \quad 32+16=48$

(we use ${ }^{49} \mathrm{Ti}$ to avoid this interference)

₹USGS 
Slide 65

\section{Interferences}

High carbon matrices (organics):

$\mathrm{CO}$ on ${ }^{28} \mathrm{Si} \quad 12+16=28$

( we use ${ }^{29} \mathrm{Si}$ )

$\mathrm{ArC}$ on ${ }^{52} \mathrm{Cr} \quad 40+12=52$

(we measure ${ }^{52} \mathrm{Cr}$ and ${ }^{53} \mathrm{Cr}$ )

₹USGS 
Slide 66

Interferences
Oxide forming matrices:
- CaO on ${ }^{56} \mathrm{Fe} \quad 40+16=56$
(we use ${ }^{54} \mathrm{Fe}$ for waters and ${ }^{57} \mathrm{Fe}$ for rocks/soils)
MoO on ${ }^{114} \mathrm{Cd} \quad 98+16=114$
$($ not a common problem $)$
USGS




\section{Memory Effects}

- Some elements have long washout times because they adsorb onto the nebulizer/spray chamber.

- Elements that form oxy-anions have memory effects; for example, W, Mo, Ta, and $\mathrm{Nb}$

- Au and Ag also have memory effects. Can use $5 \% \mathrm{HCl}$ between samples to rinse out $\mathrm{Ag}$ ( forms $\mathrm{AgCl}_{2}{ }^{-}$complex) 
Slide 68

\section{Contamination}

- Because ICP-MS is so sensitive, contamination is always a concern.

- We distill (sub-boiling) the $\mathrm{HNO}_{3}$ acid used to make standards and calibration solutions and for our digestions. Can purchase ULTREX grade $\mathrm{HNO}_{3}$

- We use 18 megohm deionized water and plastic or TEFLON $®$ labware.

- Natural water samples are easily contaminated with $\mathrm{Al}, \mathrm{Fe}, \mathrm{Zn}$.

\section{₹USGS}


Slide 69

\section{ICP-AES vs. ICP-MS}

- For rock/soil/plant/water analysis, we use ICP-AES for major elements ( $\mathrm{Na}, \mathrm{K}, \mathrm{Ca}, \mathrm{Mg}, \mathrm{Ti}, \mathrm{Mn}, \mathrm{P}, \mathrm{Fe}, \mathrm{Al})$ and ICP-MS for trace elements. In water $\mathrm{P}, \mathrm{Fe}, \mathrm{Al}$ are done by ICP-MS.

- ICP-MS is especially good for heavy trace elements (Cd, Pb, Bi, Th, U, Mo, Rb, Sr, Sn, REE) providing interferences are properly accounted for or reduced by sample preparation and introduction

- Same dissolution problems as ICP-AES: $\mathrm{FeCr}_{2} \mathrm{O}_{4}$, $\mathrm{ZrSiO}_{4}, \mathrm{BaSO}_{4}$, rutile, corundum, beryl do not dissolve completely in acids.

- Must do fusion or sinter for total REE measurements for both methods and usually need to separate and preconcentrate for ICP-AES

₹USGS

Both ICP methods yield high quality multi-elemental data. The two methods are highly compatible, each offering unique strengths and weaknesses. Both methods should be available in quality analytical laboratories. 
Slide 70

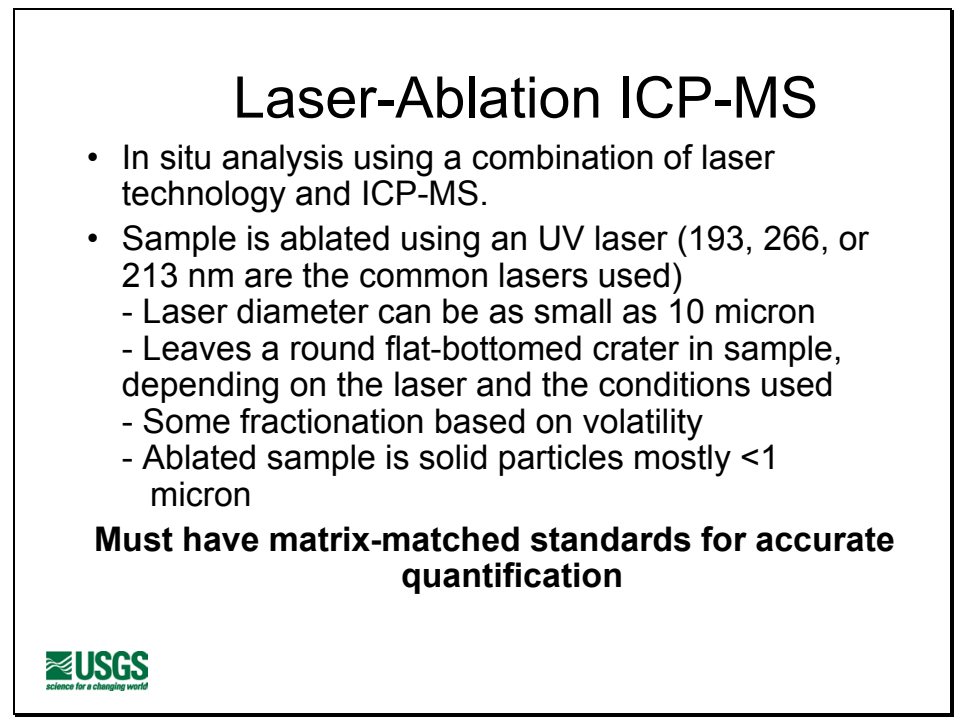

Complimentary to solution based ICP-MS methods is the laser ablation accessory. LA-ICPMS offers the determination of trace levels of many elements on the solid sample. It too has its unique problems and advantages, most in the sampling of the matrix, usually resulting from matrix inhomogeneity. 
Slide 71

\begin{tabular}{|c|c|}
\hline \multicolumn{2}{|c|}{ Current USGS Applications of LA-ICP-MS } \\
\hline Geologic & Biological \\
\hline $\begin{array}{l}\text { Siderophile trace } \\
\text { elements in sulfides }\end{array}$ & $\begin{array}{l}\text { Trace element contents of: } \\
\text { tree rings }\end{array}$ \\
\hline $\begin{array}{l}\text { Trace elements in } \\
\text { glasses }\end{array}$ & $\begin{array}{l}\text { fish otoliths } \\
\text { diatoms }\end{array}$ \\
\hline $\begin{array}{l}\text { Trace elements in } \\
\text { garnets }\end{array}$ & corals \\
\hline $\begin{array}{l}\text { Standards development } \\
\text { Methods development }\end{array}$ & $\begin{array}{l}\text { tortoise shells } \\
\text { bones }\end{array}$ \\
\hline Trace metals in coals & \\
\hline ₹USGS & \\
\hline
\end{tabular}

One of the newest tools in the toolbox of the analytical chemist, LA-ICP-MS has been applied to a myriad of novel analytical problems. It has proven to be invaluable for many diverse matrices and investigations. 


\section{X-ray Fluorescence Spectrometry}

- WD-XRF and ED-XRF

- ED-XRF is the method of choice if atomic number $>26(\mathrm{Fe})$

- Non-destructive, qualitative and quantitative determinations for major to trace levels

- Field portable, even hand-held units available

- Highly matrix dependent - fusion of samples reduces matrix problems

\section{₹USGS}

Another workhorse instrumental method is x-ray fluorescence spectrometry (XRF). There are two major methods of detection: wavelength and energy dispersive. Although commonly plagued with matrix problems, XRF methods do play an important role in the modern laboratory. $\mathrm{X}$-ray fluorescence spectrometry is commonly applied to the nondestructive analysis of environmental samples, both in the laboratory and in the field for many major, minor, and trace elements. There are basically two different types of X-ray fluorescence analysis: wavelength dispersive X-ray fluorescence (WDXRF) and energy dispersive X-ray fluorescence (EDXRF). Both techniques entail the excitation of characteristic X-rays within a sample followed by their subsequent detection and measurement. WDXRF is very precise and accurate for major and selected trace constituents in a silicate matrix. EDXRF finds applications for minor and trace element determinations and can be field portable. EDXRF is also a very fast and nondestructive qualitative and quantitative tool for measuring samples of unknown composition. It is, however, not as precise as some of the other trace element methods. In general, if an element has a lower atomic number than $\mathrm{Fe}$ (26), WDXRF is the preferred method for its determination; whereas if an element has an atomic number larger than Fe, EDXRF is the method of choice. Both methods are matrix dependent for their respective sensitivities and detection limits. 


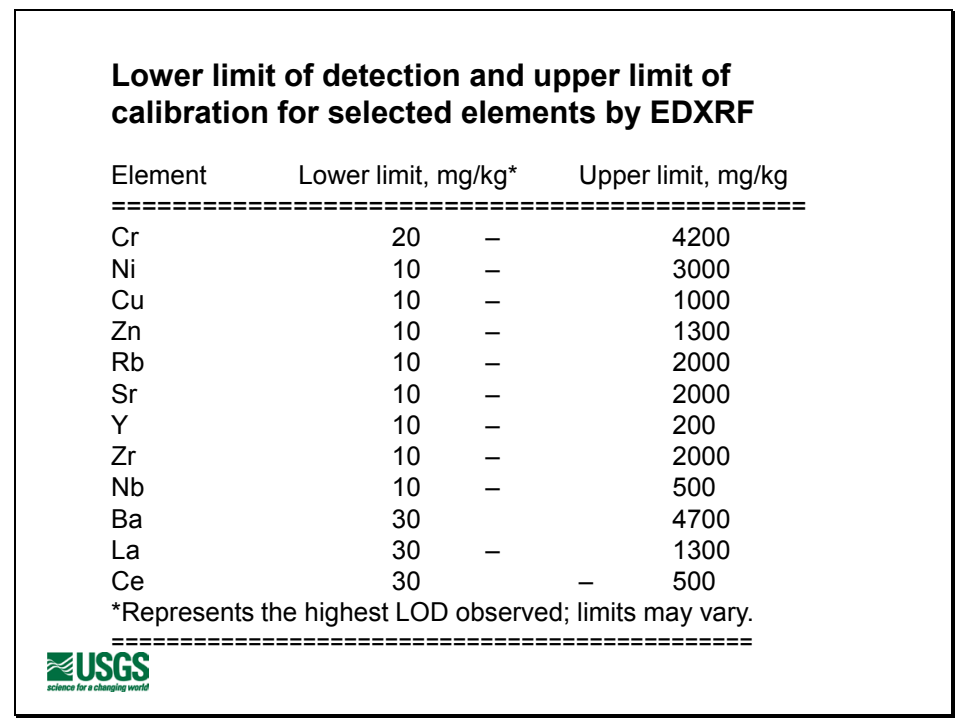

EDXRF is a method for the qualitative and quantitative analysis of elemental composition in solid or liquid samples. It is based on the instantaneous generation, detection, and measurement of characteristic X-rays emitted by the elements in a sample when the sample is bombarded with high energy X-rays. This is a nondestructive analytical process that requires little or no sample preparation. Spectral-line interferences include line overlap and absorption/enhancement effects (matrix effects). The problem of spectral-line overlap is shared by all emission and fluorescence methods. Spectral-line overlap results from the incomplete resolution of two or more spectral lines or peaks. There are two types of spectral-line overlaps in routine EDXRF analysis. The first is a $\mathrm{K} \beta$ line from one element overlapping the $\mathrm{K} \alpha$ line from the adjacent, heavier element in the periodic table (for example, $\mathrm{Ni} \mathrm{K} \beta$ overlaps $\mathrm{Cu} \mathrm{K} \alpha$ ). The second is L-series lines from one element interfering with $\mathrm{K}$ lines from another element (for example, $\mathrm{Ba} \mathrm{Lg} 1$ with $\mathrm{Cr} \mathrm{K} \alpha$ ). All these interferences can be removed by peak stripping or peak deconvolution techniques using computer algorithms. Matrix effects (absorption/enhancement) occur when radiation emitted by the analyte interacts with other components in the sample before it reaches the detector. The effects are corrected by a scattered radiation method that has been widely used for routine trace-element analysis of various geologic materials. This correction method is based on the fact that the analyteline intensity and Compton-scatter intensity are affected in the same way by differences in mass absorption coefficients from one sample to another. Although the scatter line and the analyte line intensities vary with the matrix, their ratio is constant over a wide range of matrix compositions. Furthermore, if the energy of the Compton-scatter peak lies close to the analyte line, the absorption, particle size, packing density, and instrumental effects are more effectively corrected. The matrix effect of secondary enhancement is not corrected by this method, but is usually negligible for elements with an atomic number greater than $26(\mathrm{Fe})$. Because this method is nondestructive, the sample can be used for other chemical and instrumental analyses after EDXRF analysis, providing a binder has not been used for the preparation of sample disks. 
Slide 74

\begin{tabular}{|c|c|c|c|c|}
\hline \multicolumn{5}{|c|}{$\begin{array}{l}\text { Concentration range for the } 10 \text { common rock-forming } \\
\text { oxides determined by WDXRF after a lithium } \\
\text { metaborate fusion and LOI (loss on ignition) }\end{array}$} \\
\hline & Constituent & Ran & ge & rcent) \\
\hline & $\mathrm{SiO}_{2}$ & 0.10 & - & 99.0 \\
\hline & $\mathrm{Al}_{2} \mathrm{O}_{3}$ & 0.10 & - & 28.0 \\
\hline & $\mathrm{Fe}_{2} \mathrm{O}_{3}$ & 0.04 & - & 28.0 \\
\hline & $\mathrm{MgO}$ & 0.10 & - & 60.0 \\
\hline & $\mathrm{CaO}$ & 0.02 & - & 60.0 \\
\hline & $\mathrm{Na}_{2} \mathrm{O}$ & 0.15 & - & 30.0 \\
\hline & $\mathrm{K}_{2} \mathrm{O}$ & 0.02 & - & 30.0 \\
\hline & $\mathrm{TiO}_{2}$ & 0.02 & - & 10.0 \\
\hline & $\mathrm{P}_{2} \mathrm{O}_{5}$ & 0.05 & - & 50.0 \\
\hline & $\mathrm{MnO}$ & 0.01 & - & 15.0 \\
\hline ₹USGS & LOI $\left(925^{\circ} \mathrm{C}\right)$ & 0.01 & _ & 100 \\
\hline
\end{tabular}


Slide 75

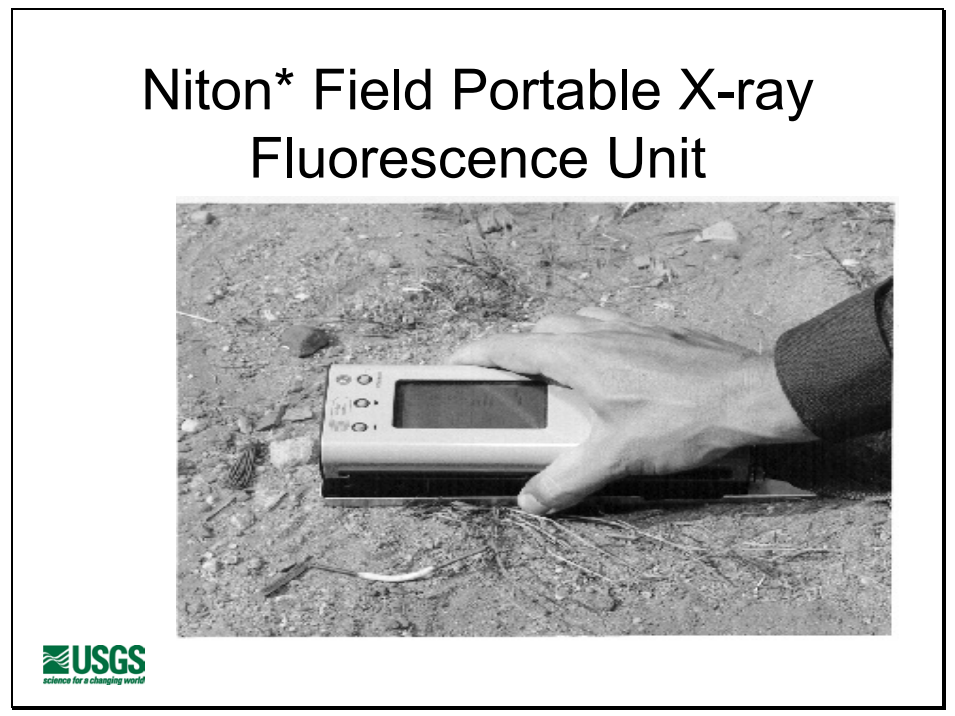

This is an example of a hand-held XRF device found to be very versatile and useful in field assessments. 
Slide 76

\begin{tabular}{|c|c|c|c|c|c|}
\hline \multicolumn{6}{|c|}{$\begin{array}{l}\text { EPA Method } 6200 \text { Detection limits for Field Portable } \\
\text { XRF (FPXRF) for the determination of elemental } \\
\text { concentrations in soil and sediment, ppm in quartz sand }\end{array}$} \\
\hline $\mathrm{Sb} \quad 40$ & $\mathrm{Fe} \quad 60$ & $\mathrm{~K}$ & 200 & $\mathrm{Rb}$ & 10 \\
\hline As 40 & $\mathrm{~Pb} \quad 20$ & $\mathrm{Se}$ & 40 & $\mathrm{Ti}$ & 50 \\
\hline $\mathrm{Ba} 20$ & Mn 70 & $\mathrm{Ag}$ & 70 & V & 50 \\
\hline Cd 100 & $\mathrm{Hg} 30$ & $\mathrm{Sr}$ & 10 & $\mathrm{Zn}$ & 50 \\
\hline $\mathrm{Ca} 70$ & Mo 10 & $\mathrm{TI}$ & 20 & $\mathrm{Zr}$ & 10 \\
\hline Cr 150 & $\mathrm{Ni} \quad 50$ & Th & 10 & & \\
\hline Co 60 & $\mathrm{Cu} 50$ & Sn & 60 & & \\
\hline$\equiv$ USGS & \multicolumn{5}{|c|}{ These are interference free detection limits. } \\
\hline
\end{tabular}

http://www.epa.gov/epawaste/hazard/testmethods/sw846/pdfs/6200.pdf is the web page for this method. From this reference: "This method is applicable to the in situ and intrusive analysis of the 26 analytes listed below for soil and sediment samples. Some common elements are not listed in this method because they are considered 'light' elements that cannot be detected by field portable x-ray fluorescence (FPXRF). These light elements are: lithium, beryllium, sodium, magnesium, aluminum, silicon, and phosphorus. Most of the analytes listed below are of environmental concern, while a few others have interference effects or change the elemental composition of the matrix, affecting quantitation of the analytes of interest. Generally elements of atomic number 16 or greater can be detected and quantitated by FPXRF." 


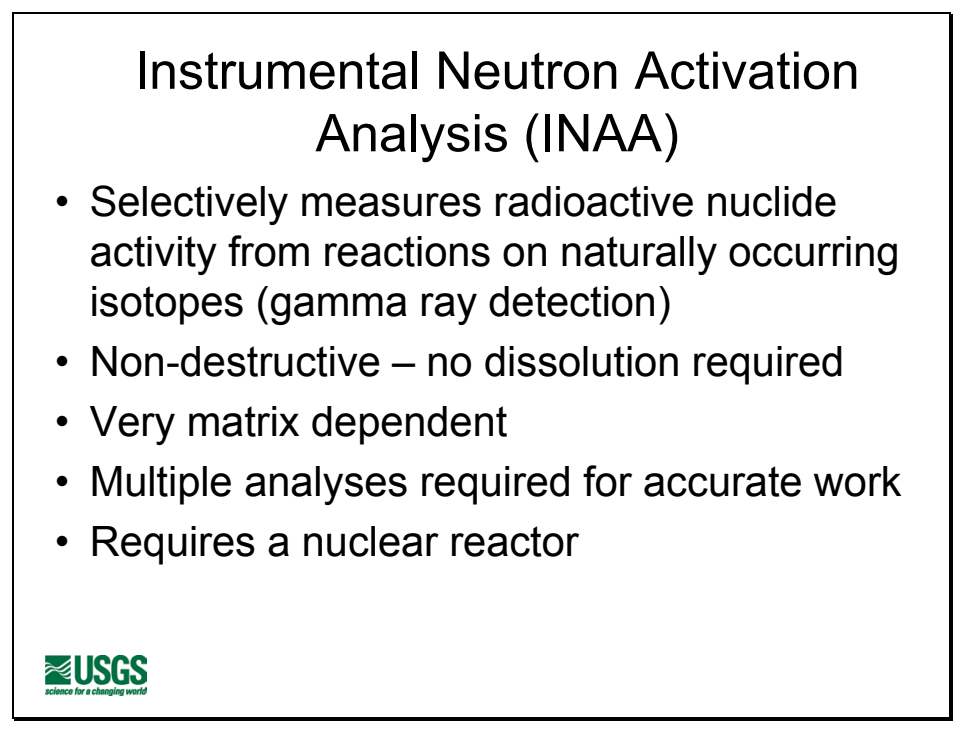

Instrumental neutron activation analysis (INAA) selectively measures radioactive nuclide activity produced by nuclear reactions on naturally occurring isotopes. The activity of the indicator radionuclide produced during irradiation is directly proportional to the amount of the element in the sample. The analytical determination is made by comparing the induced activity in the sample with well-characterized standards activated under identical conditions of neutron flux. The activities of the samples and standards are measured using gamma-ray spectroscopy. Gamma-ray radiation emitted by a radionuclide is converted into an electrical signal by a semi-conductor detector. A multichannel analyzer analyzes the electrical signal. Semiconductor detectors, such as high-purity and lithium-drifted germanium detectors are used to exploit their high resolution. Spectra produced are analyzed by software that locates peaks, identifies peaks, and calculates the area of each peak. Not all elements will be detectable for all matrixes. Samples having unusual matrixes will require adjustments to the counting protocol. A minimum of 4 months is required for completion of the analysis. The technique is "nondestructive" and the sample may, with some restrictions, be analyzed by other methods if the amount of a sample is limited. A lower limit on the concentration of an element is calculated by estimating the minimum detectable peak area above the observed background using a peak detection criterion used in a peak-fitting algorithm. The minimum detectable peak is determined by 3 sigma of the blank. Reporting limits are matrix dependent and may be higher for routine analysis. Lower reporting limits are highly matrix dependent.

Element Lower reporting limit

\begin{tabular}{|c|c|}
\hline $\mathrm{Ba}$ & 100 ppm \\
\hline $\mathrm{Na}, \mathrm{Fe}, \mathrm{Ni}, \mathrm{Sr}$ & $10 \mathrm{ppm}$ \\
\hline $\mathrm{Zn}, \mathrm{Rb}, \mathrm{Nd}$ & $1 \mathrm{ppm}$ \\
\hline $\mathrm{Cr}, \mathrm{Co}, \mathrm{Sb}, \mathrm{Cs}, \mathrm{Ce}, \mathrm{Sm}, \mathrm{Yb}, \mathrm{Th}, \mathrm{U}$ & $0.1 \mathrm{ppm}$ \\
\hline $\mathrm{Sc}, \mathrm{La}, \mathrm{Eu}, \mathrm{Tb}, \mathrm{Lu}, \mathrm{Hf}, \mathrm{Ta}$ & $0.01 \mathrm{ppm}$ \\
\hline
\end{tabular}


Now that you have a data set, how comfortable are you with it?

Just because you have an answer, it does not mean that it is the correct one!

\section{₹USGS}


Slide 79

\section{Minimization of Analytical Bias}

- Robust, documented, established methods

- Temporally consistent analytical methodologies and data archiving

- Limited number of participating analytical facilities - greatly prefer only one

- Inter-laboratory comparisons

- Generous usage of SRMs and duplicate real samples

₹USGS

The goal of all analytical procedures is to produce data of the highest quality with the least amount of error for any given study. 


\section{Quality Assurance/Quality Control Issues}

- Temporally stable methodologies!

- Critical for a long term program requiring a consistent data base

- Precision and accuracy - In-house SRMs

- Certified SRMs

- Real sample duplicates

- Analyte - Spiked materials

- Frequency of quality assessment materials

- Quantified values of critical analytes in SRMs

EUSG 
Slide 81

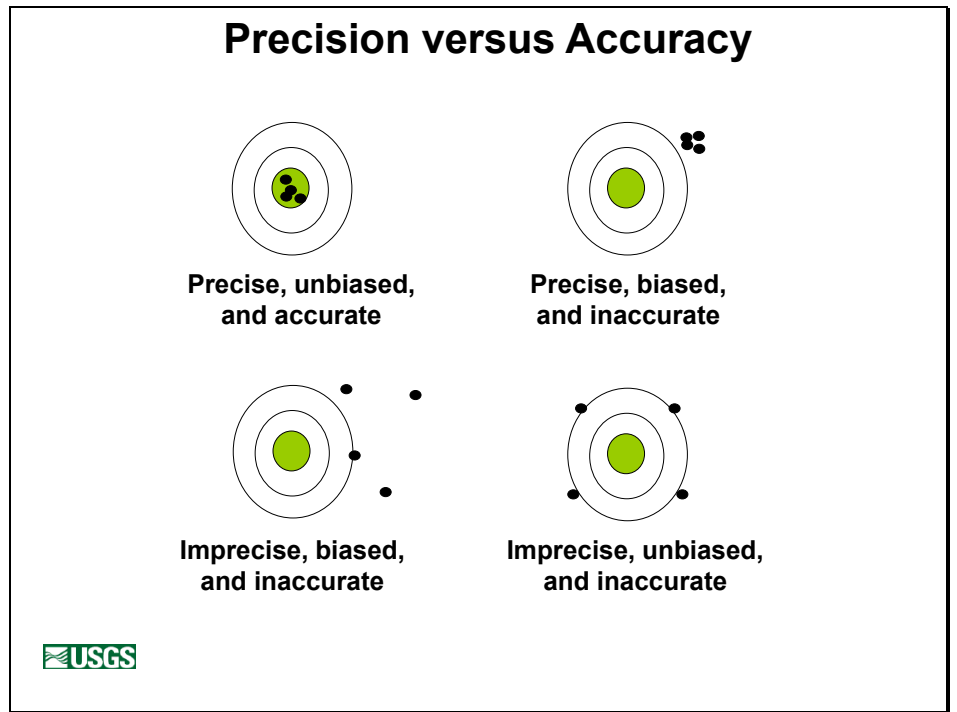

The common goal for all chemical analyses is to have data that are precise, accurate, and unbiased. The bull's eye concept depicts this above. Having good precision does not ensure good accuracy and vice versa. 
Slide 82

\section{Quality Assurance / Quality Control}

- Standard Reference Materials (SRMs) - Matrix matched in-house reference materials

- Standard Operating Procedures (SOPs)

- Replicates (laboratory and field)

- Blanks (laboratory and field)

- Spiked samples

- Documentation

₹USGS 


\section{Significant Figures}

- Never represent the measured data to be more than what they really are - do not promise precision and/or accuracy better than what was measured.

- In general, many spectroscopic detection methods are at best $2 \%$ relative. As a result, never report more than three significant figures in the raw data or any perturbations of that data.

\section{ॠUSGS}

This is a subject that has been discussed at length at numerous USGS Research Chemistry Project meetings. The bottom line is that when using analytical data, do not represent data to be more than what they really are. For example, the reality is that ICP-AES data are usually only precise to $+/-2$ percent relative error under normal circumstances. This limit of precision in ICPAES is determined by the noise of the pneumatic nebulization process which is a subject beyond the scope of this discussion. Suffice it to say that ICP-AES determinations cannot be more precise than the noisiest component in the instrument, and in this case it is the nebulizer. In our laboratory we have strongly advocated reporting three significant figures for ICP-AES determinations that are above 10 times the detection limit for a given element because rounding all ICP-AES numbers to two significant figures can introduce large rounding errors into the data. Consider the following example (keep in mind that ICP-AES data are precise to $+/-2$ percent relative):

A value of $104 \mathrm{ppm}$ (three significant figures) gets rounded to a value of $100 \mathrm{ppm}$ if one rounds to two significant figures. A value of $106 \mathrm{ppm}$ gets rounded to $110 \mathrm{ppm}$ if one rounds to two significant figures. The relative difference between $100 \mathrm{ppm}$ and $110 \mathrm{ppm}$ is 10 percent, which is $5 \mathrm{x}$ more error than was contained in the original data (do not forget that ICP-AES data is precise to 2 percent). Therefore, rounding to two significant figures can introduce unnecessary errors into the data. It used to be popular to do so because it is a very conservative approach. The best way to report the data in the above example would be $104+/-2$ ppm. However, based on the authors' collective experience of more than 70 years at the chemistry bench, if the analysts were to do this, most sample submitters would merely drop the $+/$ - data and use the numerical value alone in a spreadsheet. Therefore, everything considered, it is better to report 3 significant figures than it is to over round the data.

Another problem associated with rounding to two significant figures is that is tends to "quantize" the data. Have you ever plotted data and noticed that sometimes they look stair-stepped at certain concentration levels? Over rounding the data causes this and it causes problems (biases) when one performs a linear regression plot of the data. To further illustrate this point, when we participate in International round robin laboratory proficiency analyses (for example, GeoPT), the 
people who send our USGS laboratories the test samples ask us to report one more significant figure than we normally report. Their rationale for this request is precisely for the reason outlined above. Therefore, when we report ICP-AES data to sample submitters, we always report three significant figures at concentrations above $10 \mathrm{x}$ the detection limit. 


\section{Standard Reference Materials}

- Define and monitor accuracy and precision - quantitate the quality of the results

- Establish effective working range

- Must be analyzed routinely

- Extensive list of SRMs available for a wide range of analyte concentrations in a variety of matrices, commonly from the low ppb to percent.

\section{ZUSGS}

Not enough emphasis can be placed on the liberal usage of SRMs in any given study. Not only do they help assess the precision and accuracy of the data, but also elucidate any interference, bias, or matrix problems to the analyst. The analysis of homogeneous, well-characterized geochemical reference materials provides the backbone for the data quality of the modern environmental laboratory. Numerous agencies from around the world have prepared, characterized, and issued reference materials in a multitude of rock, ore, soil, sediment, and coal matrix types. Despite the more than 380 reference materials that have been generated, the number of geochemical reference materials of a specific sample class is limited, as is the number of highquality analyses. Nevertheless, the analysis of reference materials in method validation, instrument calibration, and quality control is essential to ensure the reliability of geochemical analyses - this fact cannot be emphasized too greatly. Accuracy of an analytical method is both a difficult and required measurement in the establishment of an analytical method. To measure accuracy, SRMs whose elemental content has been established by several independent methods are essential. Standard reference materials are intended as a control to ensure that different laboratories are analyzing the same homogeneous, well-characterized material. Several SRMs need to be analyzed to establish the complete working range of a method, both in sample matrix composition and level of the analyte. Accuracy assessments are required to establish both quality control and quality assurance for the data produced. Consult Taylor (1993) for a thorough discussion of the use of SRMs. 
Slide 85

\section{Standard Reference Materials}

- Homogeneous, well-characterized material, matrix appropriate

- Method and laboratory validation

- Instrument Calibration and Normalization

- Quality Control and Quality Assurance

- Method limitations

₹USGS

Please consult the text portion of this report for additional information and discussion of SRMs and their use in environmental studies. 
Slide 86

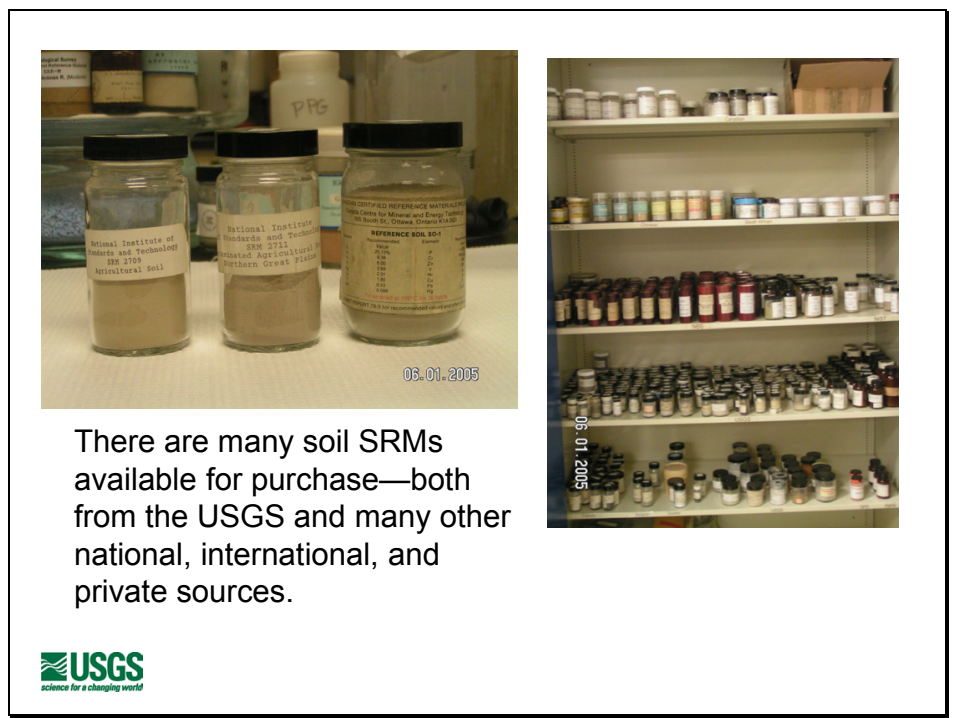


Slide 87

\section{Examples of Sources of Certified SRMs}

- CCRMP: Canadian Certified Reference Materials Project, Canada Center for Mineral and Energy Technology, Mines and Resources

- NRCC: National Research Council of Canada, Chemistry Division, National Research Council

- NIST: National Institute of Standards and Technology, Office of Standard Reference Materials

- USGS: United States Geological Survey (Contact S.A.Wilson@303-236-2454 or swilson@usgs.gov)

\section{ZUSGS}

The USGS is a world leader in the development of certified reference materials for the determination of many elements in many environmental matrices. Please see the current USGS Fact Sheet for the USGS Reference Materials at: http://pubs.usgs.gov/fs/2007/3056/pdf/fs073056_508.pdf. 
Slide 88

\begin{tabular}{|c|c|c|c|c|c|}
\hline \multicolumn{6}{|c|}{$\begin{array}{l}\text { Selected SRMs for Selenium } \\
\text { (and associated concomitant elements, all } \\
\text { concentrations as ppm)* }\end{array}$} \\
\hline & & $\mathrm{Se}$ & As & $\mathrm{Pb}$ & $\mathrm{Zn}$ \\
\hline GSS-7 & Soil & 0.32 & 4.8 & 13.6 & 142 \\
\hline MESS-2 & Sed & 0.72 & 20.7 & 21.9 & 177 \\
\hline GSS-5 & Soil & 1.56 & 412 & 552 & 494 \\
\hline SY-2 & Rock & 20 & 17.3 & 85 & 248 \\
\hline SY-3 & Rock & 30 & 18.8 & 133 & 244 \\
\hline \multicolumn{6}{|c|}{${ }^{*}$ Govindaraju (1994) } \\
\hline \multicolumn{6}{|l|}{ EUSGS } \\
\hline
\end{tabular}

SRMs can be chosen for a study in several ways:

- For a given element over a desired concentration range.

- For a given matrix, such as soils.

- For a given suite of elements.

- Combination of the above. 
Slide 89

\begin{tabular}{|c|c|c|c|c|c|c|c|}
\hline \multicolumn{8}{|c|}{$\begin{array}{c}\text { Selected Soil SRMs from CCRMP For } \\
\text { Selected Elements* }\end{array}$} \\
\hline & $\underline{\text { As }}$ & Se & $\mathrm{Cu}$ & Mo & $\underline{P b}$ & $\mathbf{Z n}$ & $\mathbf{H g}$ \\
\hline SO-1 & 2 & 0.09 & 61 & - & 20 & 144 & 0.021 \\
\hline SO-2 & 1.2 & 0.4 & 8 & - & 20 & 115 & 0.082 \\
\hline SO-3 & 2.5 & -- & 17 & - & 13 & 48 & 0.017 \\
\hline SO-4 & 7.4 & 0.49 & 21 & 1 & 14 & 94 & 0.032 \\
\hline \multicolumn{8}{|c|}{${ }^{*}$ Govindaraju (1994) } \\
\hline चUSGS & & & & & & & \\
\hline
\end{tabular}


Slide 90

ICP-MS is the Suggested Approach

- Suitable total digestion must be chosen -usually multi-acid

-must be highly oxidative to destroy organic material quickly to minimize volatility problems

- Multi-element, especially for the trace element content

- Applicable for large variation in analyte concentrations and matrices

- Usually most applicable for partial digestions because of required lower limit of determinations

- Using XRF would compliment ICP-MS for the determination of the major elements ॠUSGS 


\section{If ICP-MS is not available}

- ICP-AES is usually very applicable for most elements. ICP-AES may be more suitable for the major and minor elements.

- Will not have limits of determination at crustal abundance or less for some critical elements; that is, Mo, Cd, As, $\mathrm{Pb}, \mathrm{REE}$.

\section{₹USGS}




\section{Single Element Methods}

- Single element determinations may be the most appropriate technique; that is, $\mathrm{Hg}$ by CV-AAS or CV-AFS, Hydride Generation-AAS for Se, As, Bi, or Sb.

- Forms of Carbon and Total Sulfur by combustion/IR.

- Specific elements for topical studies; that is, nitrogen, forms of sulfur, REEs, precious metals. 
Slide 93

\section{Qualitative Information}

- ED-XRF, both laboratory-based and field methods for elemental content

- Mylar film

- Pressed pellets, with or without binders

- X-ray Diffraction - Mineralogy

- INAA

- ICP-MS elemental scans -Laser Ablation

-Solution aspiration 
Slide 94

\section{An example of a large-scale USGS} environmental program - NAWQA (National Water Quality Assessment)

- Sample analyzed: Wet-sieved in the field, $<63 \mu$ stream-bed sediment from the higher order streams of a drainage basin

- Samples are shipped moist and refrigerated to a central laboratory

- Samples are dried at ambient temperature under forced air

- Dry samples are pulverized with a ceramic plate grinder to homogenize 
Slide 95

\section{NAWQA Analytical Protocol}

- 42 elements are determined at or below crustal abundance by ICP-MS after a 4-acid digestion in an open vessel

- Hg determined by CV-AAS

- Se determined by HG-AAS

- Total S by IR-combustion

- Forms of C (IR combustion and titration)

- QA/QC: For every 40 sample job - 1 duplicate real sample, 1 stream sediment SRM (to match matrix), and 1 stream sediment SRM enriched in critical elements to ensure detection 
Slide 96

\section{Conclusions}

- The sample analyzed should represent the question being asked.

- Sensitive, accurate, and precise instrumental methods are available for a broad range of elemental determinations for use in geochemical surveys, including soil and environmental. A method of analysis should be chosen that will yield quantifiable data.

- The use of appropriate QA/QC assessment materials is essential for durable quality analyses. 


\section{Conclusions (continued)}

- Total analyses tend to be the least expensive and are the most reliable data available.

- Total and Speciation/Phase association methods are available for environmental studies of soils, but the costs may be prohibitive for regional soil surveys.

- Resources should be defined up front for this study. How much is available to get what accomplished in a given time frame? How do we prioritize the analytical portion ZUSGS Of this program? 
Slide 98

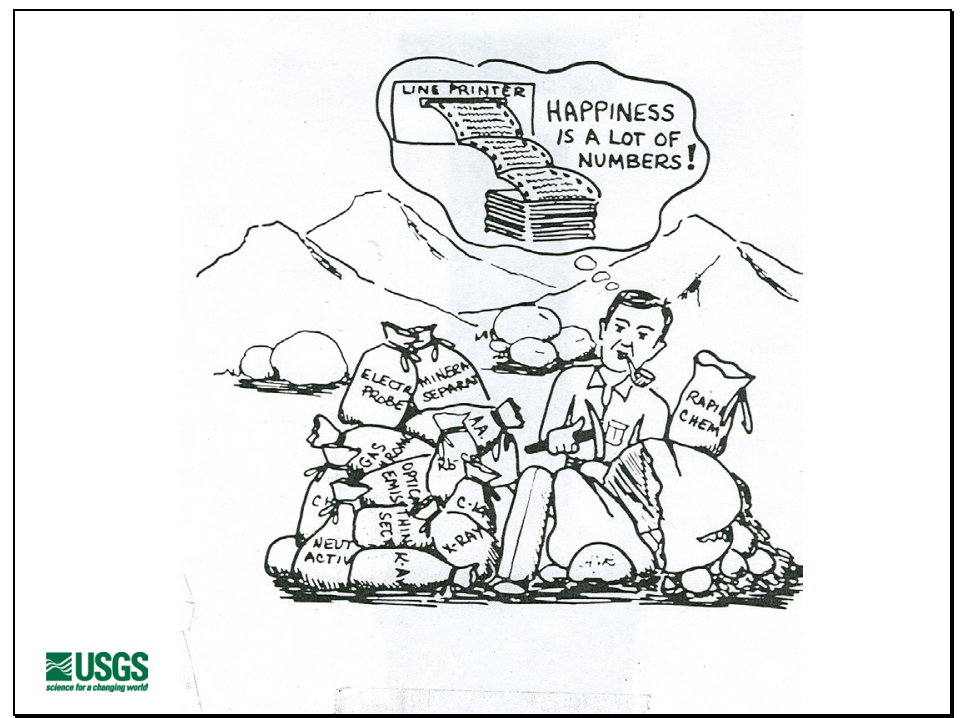

Cartoon from Rose (1979). 
Table 1. Atomic Spectroscopy detection limits (ppb or micrograms/liter).

\begin{tabular}{|c|c|c|c|c|}
\hline Element & F-AAS & GF-AAS & ICP-AES & ICP-MS \\
\hline Aluminum & 45 & 0.1 & 1 & 0.005 \\
\hline Antimony & 45 & 0.05 & 2 & 0.0009 \\
\hline Arsenic & 150 & 0.05 & 2 & 0.0006 \\
\hline Barium & 15 & 0.35 & 0.03 & 0.0002 \\
\hline Beryllium & 1.5 & 0.008 & 0.09 & 0.003 \\
\hline Bismuth & 30 & 0.05 & 1 & 0.0006 \\
\hline Boron & 1000 & 20 & 1 & 0.003 \\
\hline Bromine & & & & 0.2 \\
\hline Cadmium & 0.8 & 0.02 & 1.5 & 0.003 \\
\hline Calcium & 1.5 & 0.002 & 0.1 & 0.00009 \\
\hline Cerium & & & 1.5 & 0.0002 \\
\hline Cesium & 15 & & 3200 & 0.0003 \\
\hline Chlorine & & & & 12 \\
\hline Cobalt & 9 & 0.15 & 0.2 & 0.0009 \\
\hline Chromium & 3 & 0.004 & 0.2 & 0.002 \\
\hline Copper & 1.5 & 0.014 & 0.4 & 0.002 \\
\hline Dysprosium & 50 & & 0.5 & 0.001 \\
\hline Erbium & 60 & & 0.5 & 0.0001 \\
\hline Europium & 30 & & 0.2 & 0.00009 \\
\hline Gadolinium & 1800 & & 0.9 & 0.0008 \\
\hline Gallium & 75 & & 1.5 & 0.0002 \\
\hline Germanium & 300 & & 1 & 0.001 \\
\hline Gold & 9 & 0.15 & 1 & 0.0009 \\
\hline Hafnium & 300 & & 0.5 & 0.0008 \\
\hline Holmium & 60 & & 0.04 & 0.00006 \\
\hline Indium & 30 & & 1 & 0.0007 \\
\hline Iodine & & & & 0.002 \\
\hline Iridium & 900 & 3 & 1 & 0.001 \\
\hline Iron & 5 & 0.06 & 0.1 & 0.0003 \\
\hline Lanthanum & 3000 & & 0.4 & 0.0009 \\
\hline Lead & 15 & 0.05 & 1 & 0.00004 \\
\hline Lithium & 0.8 & 0.06 & 0.3 & 0.001 \\
\hline Lutetium & 1000 & & 0.1 & 0.00005 \\
\hline Magnesium & 0.15 & 0.004 & 0.04 & 0.0003 \\
\hline Manganese & 1.5 & 0.005 & 0.1 & 0.00007 \\
\hline Mercury & 300 & 0.6 & 1 & 0.016 \\
\hline Molybdenum & 45 & 0.03 & 0.5 & 0.001 \\
\hline Neodymium & 1500 & & 2 & 0.0004 \\
\hline Nickel & 6 & 0.07 & 0.5 & 0.0004 \\
\hline Niobium & 1500 & & 5 & 0.0009 \\
\hline Osmium & & & 6 & \\
\hline Palladium & 30 & 0.09 & 2 & 0.0005 \\
\hline Phosphorous & 75,000 & 130 & 4 & 0.1 \\
\hline
\end{tabular}


Table 1. Atomic Spectroscopy detection limits ( $\mathrm{ppb}$ or micrograms/liter).--continued

\begin{tabular}{|c|c|c|c|c|}
\hline Element & F-AAS & GF-AAS & ICP-AES & ICP-MS \\
\hline Platinum & 60 & 2.0 & 1 & 0.002 \\
\hline Potassium & 3 & 0.005 & 1 & 1 \\
\hline Praseodymium & 7500 & & 2 & 0.00009 \\
\hline Rhenium & 750 & & 0.5 & 0.0003 \\
\hline Rhodium & 6 & & 5 & 0.0002 \\
\hline Rubidium & 3 & 0.03 & 5 & 0.0004 \\
\hline Ruthenium & 100 & 1 & 1 & 0.0002 \\
\hline Samarium & 3000 & & 7 & 0.001 \\
\hline Scandium & 30 & & 2 & 0.0002 \\
\hline Selenium & 100 & 0.05 & 3 & 0.0007 \\
\hline Silicon & 90 & 1 & 10 & 0.03 \\
\hline Silver & 1.5 & 0.005 & 0.6 & 0.002 \\
\hline Sodium & 0.3 & 0.005 & 0.5 & 0.0003 \\
\hline Strontium & 3 & 0.025 & 0.05 & 0.00002 \\
\hline Tantalum & 1500 & & 1 & 0.0005 \\
\hline Tellurium & 30 & 0.1 & 2 & 0.0008 \\
\hline Terbium & 900 & & 2 & 0.00004 \\
\hline Thallium & 15 & 0.1 & 2 & 0.0002 \\
\hline Thorium & & & 2 & 0.0004 \\
\hline Thulium & 15 & & 0.6 & 0.00006 \\
\hline Tin & 150 & 0.1 & 2 & 0.0005 \\
\hline Titanium & 75 & 0.35 & 0.4 & 0.003 \\
\hline Tungsten & 1500 & & 1 & 0.005 \\
\hline Uranium & 15,000 & & 10 & 0.0001 \\
\hline Vanadium & 60 & 0.1 & 0.5 & 0.0005 \\
\hline Ytterbium & 8 & & 0.1 & 0.0002 \\
\hline Yttrium & 75 & & 0.2 & 0.0002 \\
\hline Zinc & 1.5 & 0.02 & 0.2 & 0.0003 \\
\hline Zirconium & 450 & & 0.5 & 0.0003 \\
\hline
\end{tabular}

All detection limits were determined using elemental standards in dilute aqueous solutions under optimized conditions for each individual element. All detection limits are based on a 98 percent confidence level ( 3 standard deviations). The actual detection limits observed when analyzing environmental samples would be higher due to concomitant elements and various interferences, depending on the method of choice. All data from Perkin Elmer, Inc., Waltham, MA, "Atomic Spectroscopy: A Guide to selecting the appropriate technique and system" on-line at: http://www.perkinelmer.com/Content/Manuals/GDE_InorganicAnalysis.pdf

F-AAS: $\quad$ Flame Atomic Absorption Spectrometry

GF-AAS: Graphite Furnace Atomic Absorption Spectrometry

ICP-AES: Inductively Coupled Plasma-Atomic Emission Spectrometry

ICP-MS: Inductively Coupled Plasma-Mass Spectrometry 
All detection limits are given in micrograms per liter $(\mu \mathrm{g} / \mathrm{L})$ and were determined using elemental standards in dilute aqueous solution. All detection limits are based on a 98 percent confidence level (3 standard deviations).

All atomic absorption detection limits were determined using instrumental parameters optimized for the individual element, including the use of System 2 electrodeless discharge lamps where available. Data shown were determined on a Perkin Elmer AAnalyst ${ }^{\mathrm{TM}} 800$.

All ICP-OES (Perkin Elmer OptimaTM 7000/7300) detection limits were obtained under simultaneous multi-element conditions with the axial view of a dual-view plasma using a cyclonic spray chamber and a concentric nebulizer.

Cold-vapor mercury detection limits were determined with a Perkin Elmer FIAS-100 ${ }^{\mathrm{TM}}$ or a Perkin Elmer FIAS-400 ${ }^{\mathrm{TM}}$ flow injection system with amalgamation accessory. The detection limit without an amalgamation accessory is $0.2 \mu \mathrm{g} / \mathrm{L}$ with a hollow cathode lamp, and $0.05 \mu \mathrm{g} / \mathrm{L}$ with a System 2 electrodeless discharge lamp. (The Hg detection limit with the dedicated FIMS-100 or FIMS-400 mercury analyzers is $<0.005 \mu \mathrm{g} / \mathrm{L}$ without an amalgamation accessory and $<0.0002$ $\mu \mathrm{g} / \mathrm{L}$ with an amalgamation accessory.) Hydride detection limits shown were determined using an MHS-15 Mercury/Hydride ${ }^{\mathrm{TM}}$ system.

GFAA detection limits were determined on a Perkin Elmer AAnalyst $800^{\mathrm{TM}}$ using $50 \mu \mathrm{L}$ sample volumes, an integrated platform and full STPF conditions. Graphite furnace detection limits can be further enhanced by the use of replicate injections.

Unless otherwise noted, ICP-MS detection limits were determined using a Perkin Elmer ELAN $9000^{\mathrm{TM}}$ equipped with Ryton ${ }^{\mathrm{TM}}$ spray chamber, Type II Cross-Flow nebulizer and nickel cones. All detection limits were determined using 3 -second integration times and a minimum of 8 measurements. 


\section{Acknowledgments}

The authors wish to thank the faculty of the Colorado School of Mines for the opportunity to present this material to the next generation of geoscientists. The authors also wish to thank Dr. Stephan A. Wilson for his insights and words for the SRM section of this report and for his guidance of the SRM Program of the USGS. We also thank Drs. Ruth E. Wolf and Todor Todorov of the USGS for their insightful reviews of this report.

\section{Selected References}

References cited in the text and slides of this report are listed below. Additional references are also given that will prove helpful to the reader in their understanding of the complex nature of the analyses of environmental materials and what needs to be considered in the use of analytical data in their studies.

Arbogast, B.F. (ed.), 1996, Analytical methods manual for the Branch of Geochemistry, U.S. Geological Survey: U.S. Geological Survey Open-File Report 96-525, 248 p.

Anderson, E.D., Smith, S.M., Giles, S.A., Granitto, M., Eppinger, R.G., Bedrosian, P.A., Shah, A.K., Kelly, K.D., Fey, D.L., Minsley, B.J., and Brown, P.J., 2011, Geophysical, Geochemical, and Mineralogical Data from the Pebble $\mathrm{Cu}-\mathrm{Au}-\mathrm{Mo}$ Porphyry Deposit Area, Southwest Alaska: Contributions to Assessment Techniques for Concealed Mineral Resources, U.S. Geological Survey Digital Data Series Number 608, available on-line at: http://pubs.usgs.gov/ds/608/.

Baedecker, P.A. (ed.), 1987, Methods for geochemical analysis: U.S. Geological Survey Bulletin 1770 .

Batley, G.E., 1989, Trace Element Speciation-Analytical Methods and Problems: Boca Raton, Fla., CRC Press Inc., 350 p.

Beauchemin, Diane, 2008, Inductively coupled plasma spectrometry: Analytical Chemistry, v. 80, p. 4455-4486.

Bertin, E.P., 1975, Principles and Practice of X-ray Spectrometric Analysis: New York, Plenum Press.

Bock, Rudolf, 1979, A Handbook of Decomposition Methods in Analytical Chemistry: London, International Textbook Company, $444 \mathrm{p}$.

Burguera, J.L., 1989, Flow Injection Atomic Spectroscopy, New York, Marcell-Decker, Inc.

Carter, M.R. (ed.), 1993, Soil Sampling and Methods of Analysis: Boca Raton, Fla., Canadian Society of Soil Science, Lewis Publishers, 823 p.

Chao, T.T., 1984, Use of partial dissolution techniques in geochemical exploration: Journal of Geochemical Exploration, v. 20, p. 101-135. 
Chao, T.T., and Sanzolone, R.F., 1989, Fractionation of soil selenium by sequential partial dissolution: Soil Science Society of America Journal, v. 53, no. 2, p. 385-392.

Chao, T.T., and Sanzolone, R.F., 1992, Decomposition techniques: Journal of Geochemical Exploration, v. 44, p. 65-106.

Chapin, T.P., and Wanty, R.B., 2005, Development of a solenoid pumped in situ zinc analyzer for environmental monitoring: Analytica Chimica Acta, 543, p. 199-208.

Clement, R. E. and Yang, P.W., 1999, Environmental Analysis: Analytical Chemistry, 71, p. 257R-292R.

Crock, J.G., 1996, Mercury, in Sparks, D.L. (ed.), Methods of Soil Analysis-Chemical Properties, Ch. 29, Part 1, 3rd ed.: Madison, Wis., American Society of Agronomy, Inc., p. 769-791.

Crock, J. G., 1986, An improved method for the determination of bismuth in geological materials by automated hydride generation-atomic absorption spectroscopy: Analytical Letters, 19, p. $1367-1385$.

Crock, J.G., and Severson, R.C., 1980, Four reference soil and rock samples for measuring element availability in the western energy regions: U.S. Geological Survey Circular 841, 16 p.

Crock, J.G., and Lichte, F.E., 1982, An improved method for the determination of arsenic and antimony in geologic materials by automated hydride generation-atomic absorption spectroscopy: Analytica Chimica Acta, v. 144, p. 223-233.

Crock, J.G., Lichte, F.E., and Briggs, P.H., 1983, Determination of elements in National Bureau of Standards' geological reference materials SRM 278 obsidian and SRM 688 basalt by inductively coupled argon plasma-atomic emission spectrometry: Geostandards Newsletter, v. 7, p. 335-340.

Crock, J.G., Arbogast, B.F., and Lamothe, P.J., 1999, Laboratory methods for the analysis of environmental samples, in Plumlee, G.S., and Logsdon, M.J. (eds.), The Environmental Geochemistry of Mineral Deposits, Part A-Processes, Techniques, and Health Issues: Society of Economic Geologists, Reviews in Economic Geology, v. 6A, p. 265-287.

Donaldson, E. M., 1982, Methods for the Analysis of Ores, Rocks, and Related Materials: Ottawa, Canada, Monograph 881, Canada Centre for Mineral and Energy Technology (CANMET).

Ficklin, W.H., 1983, Separation of Arsenic (III) and Arsenic (V) in ground waters by ion-exchange: Talanta, v. 30, p. 371-374.

Ficklin, W.H., 1990, Extraction and speciation of arsenic in lacustrine sediments: Talanta, v. 37, no. 8, p. 831-834.

Ficklin, W.H., and Mosier, E.L., 1999, Field methods for sampling and analysis of environmental samples for unstable and selected stable constituents, in Plumlee, G.S., and Logsdon, M.J. (eds.), 
The Environmental Geochemistry of Mineral Deposits, Part A-Processes, Techniques, and Health Issues: Society of Economic Geologists, Reviews in Economic Geology, v. 6A, p. 249-264.

Fletcher, W.K., Hoffman, S.J., Mehrtens, M.B., Sinclair, A.J., and Thomson, I. (ed.), 1986, Exploration Geochemistry-Design and Interpretation of Soil Surveys: Reviews in Economic Geology, Volume 3, the Economic Geology Publishing Company, El Paso, TX, 180 p.

Gladney, E.S., Burns C.E., and Roelandts, I., 1983, 1982 Compilation of elemental concentrations in eleven United States Geological Survey rock standards: Geostandards Newsletter, v. 7, p. 3-226.

Gladney, E.S., Burns, C.E., and Roelandts, I., 1985, 1983 Compilation of elemental concentrations data for samples SO-1 to SO-4: Geostandards Newsletter, v. 9, 35 p.

Gladney, E.S., O’Malley, B.T., Roelandts, I., and Gills, T.E., 1987, Compilation of elemental concentration data for NBS clinical, biological, geological, and environmental standard reference materials: U.S. Department of Commerce, National Bureau of Standards Special Publication, no. 260-111, p. 185, 186, 414.

Gladney, E.S., and Roelandts, I, 1990, 1988 Compilation of elemental concentration data for CCRMP reference rock sample SY-2, SY-3, and MRG-1: Geostandards Newsletter, v. 14, p. 373-458.

Gordon, G.E., Randle, K., Goles, G.G., Corliss, J.B., Besson, M.H., and Oxley, S.S., 1968, Instrumental activation analysis of standard rocks with high-resolution X-ray detectors: Geochemica et Cosmochemica Acta, v. 32, p. 369-396.

Gough, L.P., Severson, R.C., and Shacklette, H.T., 1988, Element Concentrations in Soils and Other Surficial Materials of Alaska: US Geological Survey Professional Paper 1458, 53 p.

Govindaraju, K., 1989, 1989 Compilation of working values and sample description for 272 geostandards: Geostandards Newsletter, v. 13 (Special Issue), p. 1-67.

Govindaraju, K., 1994, 1994 Compilation of working values and sample description for 383 geostandards: Geostandards Newsletter, v. 18 (Special Issue), p. 1-158.

Gustavsson, N., Bolviken, B., Smith, D.B., and Severson, R.C., 2001, Geochemical Landscapes of the Conterminous United States-New Map Presentations for 22 Elements: US Geological Survey Professional Paper 1648, 38 p., also available at: http://geology.cr.usgs.gov/pub/ppapers/p1648/.

Hageman, P.L., 2007a, TM 5-D2-Determination of Mercury in Aqueous and Geologic Materials by Continuous Flow-Cold Vapor-Atomic Fluorescence Spectrometry (CVAFS): available at http://pubs.usgs.gov/tm/2007/05D02/. 
Hageman, P.L., 2007b, U.S. Geological Survey field leach test for assessing water reactivity and leaching potential of mine wastes, soils, and other geologic and environmental materials: U.S. Geological Survey Techniques and Methods, book 5, chap. D3, 14 p., also available at http://pubs.usgs.gov/tm/2007/05D03/pdf/TM5-D3_508.pdf.

Ingamells, C.O., and Pitard, F.F., 1986, Applied Geochemical Analysis: New York, John Wiley and Sons, $733 \mathrm{p}$.

Jeffery, P.G., and Hutchison, D., 1983, Chemical Methods of Rock Analysis, 3rd ed.: Oxford, Pergamon Press, 379 p.

Johnson, R.G., 1984, Trace element analysis of silicates by means of energy-dispersive X-ray spectrometry: X-ray Spectrometry, v. 13, no. 2, p. 64-68.

Johnson, R.G., and King, B-S.L., 1987, Energy-dispersive X-ray fluorescence spectrometry, in Baedeker, P.A. (ed.), Methods for Geochemical Analysis: U.S. Geological Survey Bulletin 1770, p. F1-F5.

Kabata-Pendias, Alina and Pendias, H.K., 2001, Trace Elements in Soils and Plants, $3^{\text {rd }}$ ed.: Boca Raton, FL, CRC Press, 413 p.

Keith, L.H. (ed.), 1988, Principles of Environmental Sampling: ACS Professional Reference Book, American Chemical Society, Washington, D.C., 458 p.

Keith, L.H. (ed.), 1992, Compilation of USEPA's Sampling and Analysis Methods: Chelsea, MI, Lewis Publishers, Inc., 803 p.

Kennedy, K.R., and Crock, J.G., 1987, Determination of mercury in geological materials by continuous-flow, cold-vapor, atomic absorption spectrophotometry: Analytical Letters, v. 20, p. 899-908.

King, B.W., 1987, Determination of trace elements in eight Chinese stream-sediment reference samples by energy-dispersive X-ray spectrometry: Geostandards Newsletter, v. 11, no. 2, p. 193-195.

Kingston, H.M., and Jassie, L.B. (eds.), 1988, Introduction to Microwave Sample PreparationTheory and Practice: American Chemical Society, Washington, DC, 263 p.

LaFleur, P.D. (ed.), 1976, Accuracy in trace analysis — sampling, sample handling, analysis, v. II: National Bureau of Standards (currently the National Institute of Standard Technology), Gaithersburg, Md., 1304 p.

Laul, J.C., 1979, Neutron activation analysis of geological materials: Atomic Energy Review, v. 17, p. 93-114. 
Lichte, F.E., 1995, Determination of elemental content of rocks by laser ablation inductively coupled plasma mass spectrometry: Analytical Chemistry, vol. 67, p. 2479-2485.

May, T.W., and Wiedmeyer, R.H., 1998, A table of polyatomic interferences in ICP-MS: Atomic Spectroscopy, v. 19, no. 5, p. 150-155.

Minczewski, J., Chwastowska, J., and Dybczynski, R., 1982, Separation and Preconcentration Methods in Inorganic Trace Analysis: Chichester, England, Ellis Horwood Limited, 543 p.

Mitra, Somenath (ed.), 2003, Sample Preparation Techniques in Analytical Chemistry: Hoboken, NJ, Wiley-Interscience, $458 \mathrm{p}$.

Montaser, Akbar and Golightly, D.W., 1992, Inductively Coupled Plasmas in Analytical Atomic Spectroscopy: New York, VCH Publishing, Inc., 1017 p.

Montaser, Akbar (Ed.). 1998, Inductively Coupled Plasma Mass Spectrometry: New York, Wiley$\mathrm{VCH}, 964 \mathrm{p}$.

Motooka, J.M., 1988, An exploration geochemical technique for the determination of preconcentrated organometallic halides by ICP-AES: Applied Spectroscopy, v. 42, p. 1293-1296.

Potts, P.J., 1987, A handbook of silicate rock analysis: London, Blackie and Son Ltd., 622 p.

Potts, P.J., Tindle, A.G., and Webb, P.C., 2000, Geochemical Reference Material Compositions Rocks, minerals, sediments, soils, carbonates, refractories, and ores in research and industry: Boca Raton, FL, Whittles Publishing and CRC Press, 313p.

Pitard, F.F., 1993, Pierre Gy's sampling theory and sampling practice-Heterogeneity, sampling correctness, and statistical process control (2d ed.): Boca Raton, FL, CRC Press, 488 p.

Potts, P.J., Tindle, A.G., and Webb, P.C., 1992, Geochemical Reference Materials Compositions: Boca Raton, FL, CRC Press Inc., 313 p.

Rose, H.J., 1979, On the care and feeding of analytical chemists: Applied Spectroscopy, v. 33, no. 9 , p. 312-317.

Rose, A.W., Hawkes, H.E., and Webb, J.S., 1979, Geochemistry in mineral exploration (2 ${ }^{\text {nd }}$ edition): New York, Academic Press, 657 p.

Sandell, E.B., 1959, Colorimetric Determinations of Traces of Metals: New York, Interscience Publishers, Inc., 1032 p.

Shacklette, H.T. and Boerngen, J.G., 1984, Element Concentrations in Soils and Other Surficial Materials of the Conterminous United States: US Geological Survey Professional Paper 1270, $105 \mathrm{p}$. 
Skoog, D.A., Hollar, F.J., and Crouch, S.P., 2006, Principles of instrumental Analysis, $6^{\text {th }}$ edition: Pacific Grove, CA, Thomson Brooks/Cole Publishers, 1039 p.

Smith, K.A. (ed.), 1983, Soil Analysis - Instrumental Techniques and Related Procedures: New York, Marcel Dekker, Inc., 562 p.

Smith, K.S., and Huyck, H.O., 1999, An overview of the abundance, relative mobility, bioavailability, and human toxicity of metals, in Plumlee, G.S., and Lodgson, M.J. (eds.), The Environmental Geochemistry of Mineral Deposits, Part A-Processes, Techniques, and Health Issues: Reviews in Economic Geology, v. 6A, Society of Economic Geologists, Inc., Littleton, CO, p. 29-70.

Smith, Roy-Keith, 1994, Handbook of Environmental Analysis, $2^{\text {nd }}$ Edition: Schenectady, NY, Genium Publishing Corp., 350 p.

Smoley, C.K., 1992, Methods for the determination of metals in environmental samples:

Environmental Monitoring Systems Laboratory, Office of Research and Development, U.S. Environmental Protection Agency, Cincinnati, Ohio, 305 p.

Sparks, D.L. (ed.), 1996, Methods of soil analysis - Chemical properties, Part 1, 3rd ed.: American Society of Agronomy, Inc., Madison, Wis., 1390 p.

Stoch, Harry, 1986, A Manual of Analytical Methods Used at Mintek: Council for Mineral Technology (MINTEK), Special Publication No. 7, Private Bag X3015, Randburg, 2125 South Africa, $426 \mathrm{p}$.

Sylvester, Paul (ed.), 2008, Laser Ablation-ICP-MS in the Earth Sciences-Current Practices and Outstanding Issues: Mineralogical Association of Canada, Short Course Series, v. 40, Quebec, Canada, $348 \mathrm{p}$.

Sulcek, Zdenek, and Povondra, Pavel, 1989, Methods of Decomposition in Inorganic Analysis: Boca Raton, Fla., CRC Press, Inc., 325 p.

Taylor, John K., 1993, Standard Reference Materials: handbook for SRM users, NIST Special Publication 260-100, available online at: http://ts.nist.gov/MeasurementServices/ReferenceMaterials/upload/SP260-100.pdf.

Thompson, M., Simon, C., and Bret, L., 1989, Calibration studies in laser ablation microprobeinductively coupled plasma atomic emission spectrometry: Journal of Atomic Spectroscopy, v. 4, p. 11-16.

Taggart, J.E., Jr., (ed.), 2002, Analytical methods for chemical analysis of geological and other materials, U.S. Geological Survey: U.S. Geological Survey Open-File Report 2002-0223, available at http://pubs.usgs.gov/of/2002/ofr-02-0223/. 
Thompson, Michael, and Walsh, J.N., 1989, A Handbook of Inductively Coupled Plasma Spectrometry, 2nd ed.: Blackie, London, 316 p.

Varma, Asha, 1984, CRC Handbook of Atomic Absorption Analysis, v. I and II: Boca Raton, Fla., CRC Press, Inc., 510 p.

Viets, J.G., and O'Leary, R.M., 1992, The role of atomic absorption spectrometry in geochemical exploration: Journal of Geochemical Exploration, v. 44, p. 107-138.

Welz, Bernhard, 1985, Atomic Absorption Spectrometry: Deerfield Beach, FL., VCH Publishers, $506 \mathrm{p}$.

Westerman, R.I. (ed.), 1990, Soil Testing and Plant Analysis: Soil Science Society of America, Inc., Madison, Wis., 784 p.

Williams, S.E., and Funston, R.S., 1987, Mercury, in Williams, R.D., and Schuman, G.E. (eds.), Reclaiming Mine Soils and Overburden in the Western United States-Analytical Parameters and Procedures: Soil Conservation Society of America, Ankeny, Iowa, p. 313-323.

Winge, R. K., Fassel, V.A., Peterson, V.J., and Floyd, M.A., 1985, Inductively Coupled PlasmaAtomic Emission Spectrometry_-An Atlas of Spectral Information: New York, Elsevier, 584 p.

Wolf, R.E., and Wilson, S.A., 2007, USGS Reference Materials Program-Serving the needs of the global analytical community: U.S. Geological Survey Fact Sheet 2007-3056, available at http://pubs.usgs.gov/fs/2007/3056/pdf/fs07-3056_508.pdf.

Zhou, C. Y., Wong, M.K., Koh, L.L., and Wee, Y.C., 1997, Evaluation of high-pressure microwave digestion methods for hydride-generation atomic-absorption spectrometric determination of total selenium and arsenic in sediment: Mikrochimica Acta, v. 127, no. 1-2, p. 77-83. 